\title{
PLA/PLGA nanoparticles prepared by nano spray drying
}

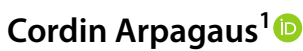

Received: 7 March 2019 / Accepted: 9 April 2019 / Published online: 16 April 2019

(c) The Author(s) 2019, corrected publication 2019

\begin{abstract}
Background Spray drying is a relatively simple, fast, reproducible and scalable drying technology that is suitable for drying heat-sensitive biopharmaceutical compounds. In view of the rapid progress of nanoencapsulation technologies in the pharmaceutical sector, nano spray drying is used in research to improve the powder formulation and release of active ingredients. The Nano Spray Dryer B-90 of the Swiss company Büchi Labortechnik AG extends the size of the powder particles produced into the nanometer scale with narrow size distributions and high encapsulation efficiency.

Area covered This study explains the special nano spray drying technology and discusses the influence of the respective process parameters on the powder properties. Applications of nano spray drying for the formulation and encapsulation of active ingredients in PLA/PLGA biopolymers are investigated and discussed. Optimized process parameters for the application of nano spray drying of similar substances are presented.

Expert opinion The analyzed studies show the possibility of producing PLGA particles from approx. $2 \mu \mathrm{m}$ to below $200 \mathrm{~nm}$ by nano spray drying, as well as the encapsulation of various active ingredients in spherical particles and nano-in-nanoparticle composite structures made of PLGA polymers for controlled drug delivery systems. The researched applications are primarily in the therapeutic field, such as the treatment of inhalation diseases, inflammations, cancer, immune diseases, genetic disorders, the regulation of vasodilatation or the surface coating of medical implants with biocompatible PLGA nanoparticles.
\end{abstract}

Keywords Nano spray drying $\cdot$ Nanoparticles $\cdot$ Encapsulation $\cdot$ Drug delivery $\cdot$ PLA $\cdot$ PLGA

\section{Introduction}

\section{PLA/PLGA biopolymers}

In the past decades, biopolymers based on lactic acid and glycolic acid and their copolymers have attracted great interest in various medical applications, e.g. as biodegradable implants in surgery with variable mechanical strength, as raw materials for wound closure products that are completely absorbed by the body, or as drug carrier substances for the production of drug delivery systems with excellent biocompatibility, adjustable degradation rate and non-toxicity in humans (Sharma et al. 2016).

In particular, polylactic acid (PLA) is applied for sutures, stents, dialysis media, drug delivery devices and tissue

Cordin Arpagaus

cordin.arpagaus@ntb.ch

1 NTB University of Applied Sciences of Technology Buchs, Institute for Energy Systems, Werdenbergstrasse 4, 9471 Buchs, Switzerland repair. PLA is a colourless, glossy and stiff thermoplastic biopolymer that is degraded by simple hydrolysis of the ester bond (Garlotta 2001; Kulkarni et al. 1966).

Poly(lactic-co-glycolic acid) (PLGA) is a copolymer of PLA and polyglycolic acid (PGA) and, in terms of design and performance, the preferred candidate of biodegradable polymers for drug delivery (Sharma et al. 2016). Body fluids degrade the polymers by hydrolysis into metabolite monomers lactic acid and glycolic acid (Danhier et al. 2012). By modification of molecular weight and polymer composition, the degradation rate and mechanical stability can be adopted to the individual requirements of the medical application. PLGA biopolymers are commercially available and approved by the US FDA (Food and Drug Administration) and EMA (European Medicines Agency) for human use at various molecular weights and lactide/glycolide ratios (Danhier et al. 2012; Sharma et al. 2016; Wan and Yang 2016). Different forms of PLGA can be obtained by varying the ratio of lactide to glycolide during the polymerization reaction, e.g. PLGA 50:50 refers to a copolymer of 50\% lactic acid and $50 \%$ glycolic acid. The glass transition temperature $\left(T_{g}\right)$ 
is an important parameter of the polymer, which decreases with higher glycolide amount. Depending on the molecular weight and the lactide to glycolide ratio, the degradation time of the polymer may vary. Low molecular weight polymers with higher glycolide content are more hydrophilic and amorphous and therefore have a shorter degradation time (Sharma et al. 2016).

\section{Spray drying of PLA/PLGA microparticles}

Spray drying is a successfully applied process in pharmaceutical technology for the production of dry powder for drug delivery systems (Conte et al. 1994). Compared to other common processes for microencapsulation, like emulsification, solvent evaporation or phase separation (Danhier et al. 2012; Wan and Yang 2016), spray drying is a fast, reproducible and scalable technology, which is suitable for drying solutions, suspensions or emulsions (Masters 1991). It is a continuous production process that enables mild temperature conditions (Pavanetto et al. 1993) and is less dependent on the solubility of the drug and the biopolymer than other microencapsulation techniques such as phase separation or solvent evaporation (Bodmeier and Chen 1988).

The main advantages of spray drying for pharmaceutical encapsulation applications can be summarized as follows (Arpagaus et al. 2013, 2017; Wong and John 2015):

- control of particle size, shape, and morphology (i.e. amorphous/crystalline form, porosity)

- one-step and continuos process to directly convert various liquid feeds into dry powders

- process simplicity and ease of operation

- low operating costs, energy efficient technology, and fast process

- possible scale-up capability

- open and closed cycle design for aqueous and organic solvents spray drying

- processing of heat-sensitive substances with low risk of degradation

- design of particles with controlled drug release properties

- high encapsulation efficiency and extended shelf life

- versatile technique for the formulation of nanocapsules with various encapsulating excipients

Spray drying has been used in several research studies to encapsulate active ingredients in PLA/PLGA biopolymers. Table 1 gives an overview of scientific work on the production of microparticles with the laboratory Mini Spray Dryer B-190, B-191 and B-290 of Büchi Labortechnik AG (Arpagaus and Schafroth 2007, 2008, 2011; EVONIK 2011). Short processing times make table-top spray drying suitable for the first feasibility trials in the laboratory.
The application spectrum includes drug encapsulation for the treatment of various diseases, such as:

- cancer (Blanco et al. 2005; Feng et al. 2004; Fu et al. 2001; Pamujula et al. 2004; Pavanetto et al. 1993; Wang and Wang 2002),

- tuberculosis (O'Hara and Hickey 2000),

- inflammation (Wagenaar and Müller 1994),

- lung infections (Rivera et al. 2004),

- asthma, or lung therapy (Schöttle 2006).

The reported particles sizes were between 1 to $15 \mu \mathrm{m}$, thus in the micron-range, suitable e.g. for inhalation drug delivery. Particles smaller than approx. $1 \mu \mathrm{m}$ pass the separation cyclone of the spray dryer and reach the outlet filter directly (Arpagaus and Schafroth 2007, 2011). High encapsulation efficiencies of up to $100 \%$ are observed (Feng et al. 2004; Fu et al. 2001; Pamujula et al. 2004; Pavanetto et al. 1993; Rivera et al. 2004; Wagenaar and Müller 1994; Wang and Wang 2002) with considerable yields of 20 to $75 \%$ (Schöttle 2006). Most of the product loss can be found as deposits in the spray chamber and in the outlet filter after the cyclone (Arpagaus and Schafroth 2007).

For the production of the spray dried microparticles, the PLA/PLGA biopolymers are dissolved in various organic solvents such as dichloromethane (DCM), chloroform (CFM), ethylacetate, or ethylformat. DCM is chosen for its high solvation capacity for PLA/PLGA biopolymers (Youan 2004) and its low boiling point of $40^{\circ} \mathrm{C}$. It is also considered as one of the least toxic halogenated solvents (Blanco et al. 2005). In addition, evaporation at temperatures lower than the glass transition temperature (PLGA: 37 to $54{ }^{\circ} \mathrm{C}$, Schafroth et al. 2012, PLA $<60^{\circ} \mathrm{C}$, Baras et al. 2000) helps to avoid adhesion and agglomeration problems. Polymer type, solid concentration and drying temperature were varied according to the process conditions listed in Table 1. The total weight of spray dried polymer powder is typically in the order of $10 \mathrm{~g}$ per batch (Arpagaus and Schafroth 2007, 2008, 2011). Proteins and enzymes were stabilized well in the dried state of the PLGA biopolymer powder by addition of glass forming stabilizers, such as trehalose (Johansen et al. 2000), sucrose (Youan 2004) or polyvinyl alcohol (PVA) (Baras et al. 2000).

In-vitro drug release from the microparticles were altered by the selection of the used copolymer composition (i.e. lactide to glycolide ratio) and molecular weight. PLGA with a higher glycolide content provided a faster release of the drug as water entered the more hydrophilic polymer chains faster compared to the more hydrophobic PLA. The literature data show that the release profiles typically had two phases (Blanco et al. 2005; Feng et al. 2004; Fu et al. 2001; Pavanetto et al. 1993; Rivera et al. 2004; Wagenaar and Müller 1994; Wang and Wang 2002). At the beginning there was 


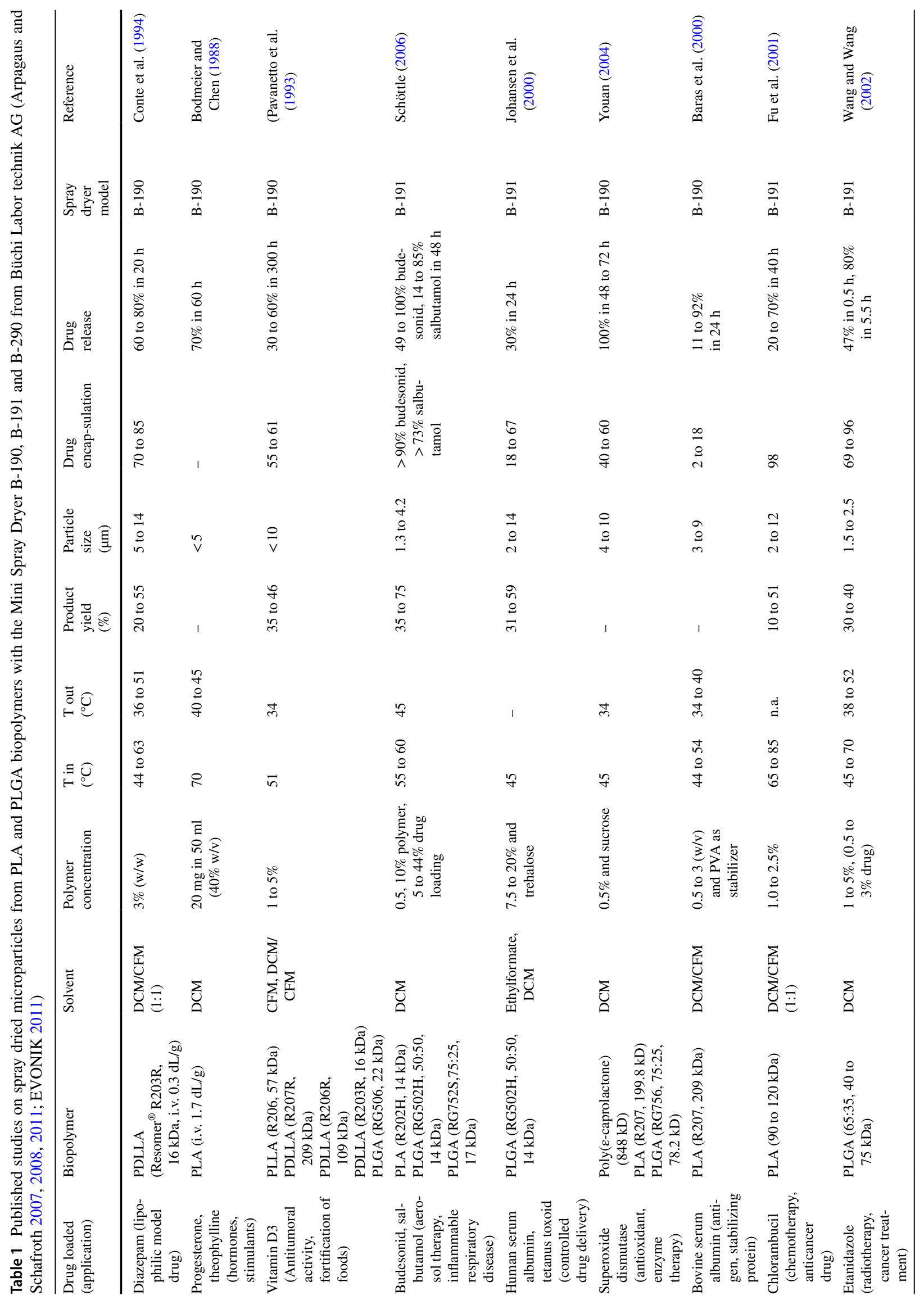




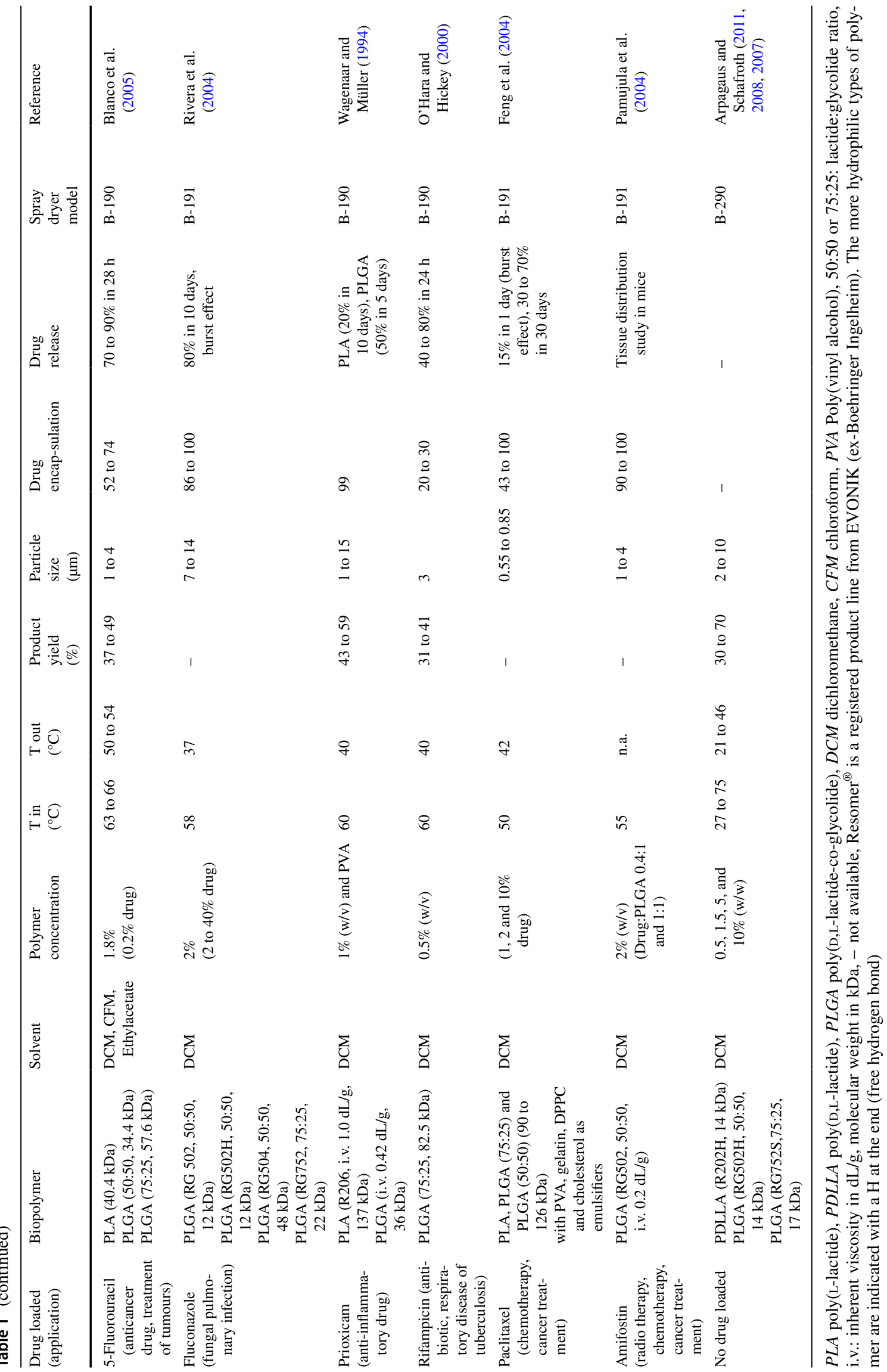


a steep increase followed by a second phase of sustained release, which was determined by diffusion of the active substance through small pores or channels in the polymer matrix (O'Hara and Hickey, 2000). The so-called "burst effect" of about 20 to $60 \%$ at the beginning was attributed to the release of drugs from the surface area of the microparticles. Typically, the release rates were lower at higher drying gas inlet temperatures (e.g. due to denser polymer matrix), higher drying gas flow rates (e.g. smaller particle sizes), lower polymer concentrations (e.g. lower porosity) and lower drug loads (e.g. fewer pores, less diffusion) (Arpagaus and Schafroth 2007, 2008, 2011).

\section{Trend towards Nano Spray Drying}

The recent advances in nanomedicine and nanotherapy have increased the pressure on the development of spray drying technology that enables the production of nanoscale particles with narrow size distribution and high yields for valuable drugs. In the pharmaceutical technology, nanoparticles are generally defined as solid colloidal particles with sizes below $1 \mu \mathrm{m}$ (Kaialy and Al Shafiee 2016; Lee et al. 2011; Li et al. 2010; Wong, 2015; Wong and John, 2015). Compared to microparticles, the smaller size and higher specific surface area improve dissolution and absorption rate and lead to higher bioavailability of the encapsulated drug (Lee et al. 2011). Over the past 10 years, there has been a remarkable growth in research activities in the field of nano spray drying. A search in the online databases of Web of Science and SCOPUS on the subject of "nano spray drying" resulted in 658 and 720 hits respectively from the years 1997 to 2017 (Fig. 1, A).

In 2017, the number of publications rose to around 100. The trend suggests that more and more products will be developed in the coming years. The potential of nano spray drying has obviously not yet been fully exploited.
Considerable research activities on nano spray drying are taking place worldwide, particularly in the fields of pharmaceuticals, material technology and bioactive food ingredients. The trend in spray drying with specific delivery strategies is towards nanoparticles, microparticles and solid dispersions (Fig. 1B). Numerous reviews and book chapters have already been published on the subject of nano spray drying technology Arpagaus 2011, 2012, 2018a, b, c, d; Arpagaus et al. 2017, 2018; Assadpour and Jafari 2019; Heng et al. 2011; Lee et al. 2011).

\section{Objectives}

The aim of this study is to investigate in particular the potential of nano spray drying biodegradable PLA/PLGA particles. First, the specialized technology of nano spray drying for the stabilization of active ingredients will be presented. Then, the influence of the process parameters on the respective powder properties for a successful nano spray drying of PLA/PLGA biopolymers is discussed. The study emphasizes especially the possibility of reducing the size of spray dried particles by an order of magnitude to the nanoscale (e.g. submicron particle sizes). Finally, the latest laboratory applications of nano spray drying for the formulation and encapsulation of various drugs will be presented using PLA/ PLGA biopolymers. An overview of the obtained particle morphology, encapsulation efficiency, drug loading and release is provided.

\section{Nano spray drying technology}

\section{Process steps and implemented technologies}

The process steps of a nano spray dryer are essentially the same as in a traditional spray dryer, which includes:
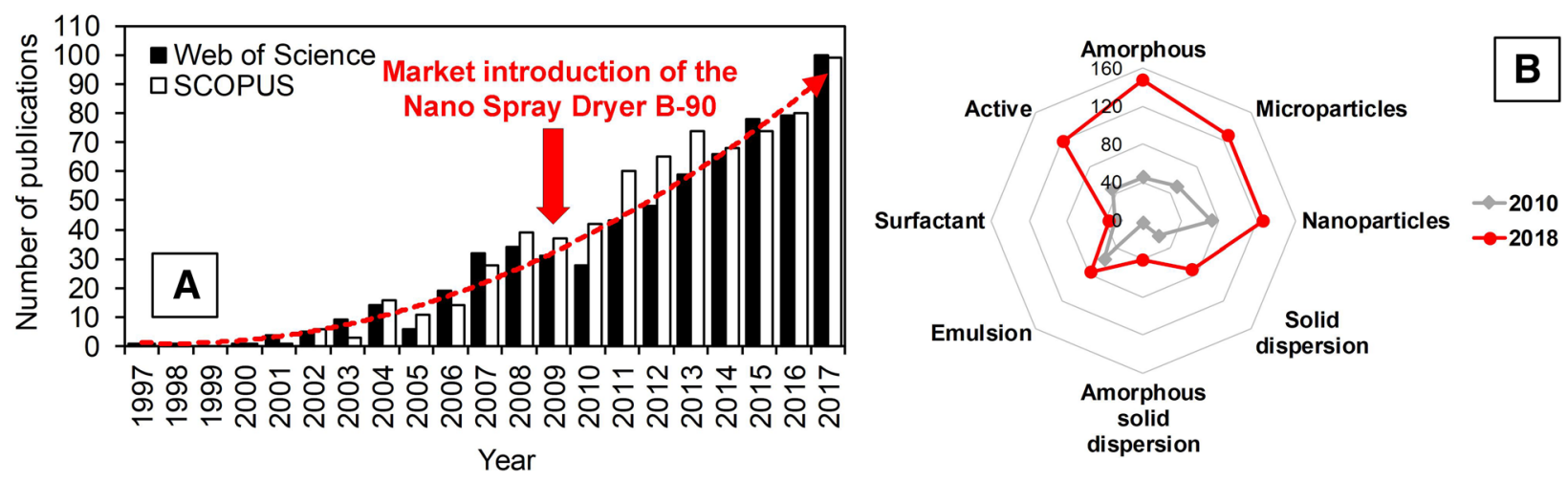

Fig. 1 A Trend in published papers in the online databases of Web of Science (www.webofscience.com) and SCOPUS (www.scopus.com) with the subject "Nano Spray Drying" since 1997 (accessed on
December 31, 2018). B Trend in spray drying publications with specific delivery strategeis for the years 2010 and 2018 (Source: SCOPUS with TITLE-ABS-KEY “spray drying” AND “...”) 
(1) heating of the drying gas,

(2) droplet formation by atomization of the fluid supply,

(3) drying of the droplets in the drying gas and formation of dry particles, and

(4) particle separation and collection of the dry particles from the drying gas.

Compared to a traditional spray dryer, some technological modifications in the experimental setup are necessary to produce and collect nanoscale particles, i.e.:

(1) the nozzle system must be able to produce smaller droplets,

(2) the drying gas flow needs to be gentle, laminar, and co-current with the sprayed droplets, and

(3) the particle collector must be highly efficient in separating submicron particles.

In 2009, the Swiss company Büchi Labortechnik AG launched the laboratory-scale Nano Spray Dryer B-90 for producing small quantities of submicron powder from a solution, nanoemulsions or nanosuspensions in the gramscale with very narrow distributions and high yields (Arpagaus 2009; Arpagaus et al. 2009). Figure 2 shows the setup and explains the implemented technologies for spray generation, heating of the drying gas, and particle collection.

\section{Droplet generation by vibrating mesh technology}

Droplet generation is based on vibration mesh technology developed for inhalation therapy. A piezoelectric actuator vibrates a thin spray mesh which contains an array of laser drilled holes in the center (approximately 1500 holes in a $5.5 \mu \mathrm{m}$ spray mesh). The vibration at ultrasonic frequency (adjustable from 80 to $140 \mathrm{kHz}$ ) deforms the mesh into the fluid side, loads the holes with fluid and pushes the fluid through the mesh into the drying chamber (Fig. 2). The output are fine low-velocity droplets with very narrow size distribution. Approximately 100 million precisely dimensioned droplets are produced per second assuming a vibration frequency of $100 \mathrm{kHz}$ and 1000 active holes in the spray mesh. The uniformity of the droplet size is mainly defined by the uniformity of the holes. The 1st generation spray head of the Nano Spray Dryer B-90 can be equipped with 4.0, 5.5, and $7.0 \mu \mathrm{m}$ spray meshes. The 2nd generation in the Nano Spray Dryer B-90 HP (market launched in 2017) offers nebulizers in small, medium, and large size, which are optimized for higher productivity and better handling during installation and replacement.

The size of the droplets is mainly influenced by the mesh size, the sample concentration, and the physicochemical properties of the fluid, such as viscosity and surface tension. The mean droplet size of water is approximately 4.8 ,
6.2 and $7.2 \mu \mathrm{m}\left(\operatorname{SPAN}\left(\mathrm{d}_{90}-\mathrm{d}_{10}\right) / \mathrm{d}_{50}\right.$ from 1.1 to 1.3 , reproducibility $\pm 0.5 \mu \mathrm{m}$ ) using a spray mesh with $4.0,5.5$ and $7.0 \mu \mathrm{m}$ holes, respectively (Arpagaus et al. 2017; Schmid 2011; Schmid et al. 2011). The maximum liquid viscosity is about 5 to $10 \mathrm{cP}$ (Arpagaus et al. 2010a). Some solutions may be too viscous to pass through the mesh, which may result in intermittent droplet generation or even blocking of droplet generation (Draheim et al. 2015). Obviously regular cleaning of the spray mesh and the nebulizer are necessary to maintain an efficient function (Arpagaus et al. 2017; Schmid 2011).

\section{Drying of the fine droplets}

The drying gas is heated to the set inlet temperature $\left(T_{i n}\right)$ in a compact heater on the top of the nano spray dryer. The heating unit consists of a porous metal foam with an integrated electric heating coil. The porous metal surface creates a laminarisation of the gas flow for gentle drying of the sprayed droplets. This is crucial because turbulence would lead to uncontrolled spray formation and particle deposits on the side walls of the drying chamber. A modular glass assembly of the drying cylinders allows simple modification of the drying chamber length. The Nano Spray Dryer B-90 can be operated in a closed mode with the Inert Loop B-295 (Fig. 3). This allows drying solutions or suspensions of organic solvents in a fully gas recirculating system, maximizing user safety and minimizing solvent consumption. The oxygen concentration is controlled below $4 \%$. Normally nitrogen is used as inert gas, while a small amount of carbon dioxide is added to prevent dielectric breakdown at the collecting electrode.

\section{Electrostatic particle collection}

The droplets are injected into the drying gas at the top of the nano spray dryer. The laminar gas flow directs the dried particles to an electrostatic particle collector, which consists of a smooth stainless steel cylinder (anode $=$ particle collec tion electrode) and a star-shaped counter electrode (cathode) inside the cylinder (Fig. 2). During the nano spray drying process, a high voltage of approximately $15 \mathrm{kV}$ is applied between the two electrodes and the dried particles are electrically charged and deflected to the inner wall of the collecting electrode. The electrostatic particle collector is able to capture submicron particles at a separation efficiency greater than $99 \%$ for small powder batches of $10 \mathrm{mg}$ to $2.7 \mathrm{~g}$ (Arpagaus et al. 2010b; Arpagaus and Meuri 2010; Bürki et al. 2011; Lee et al. 2011; Li et al. 2010; Schmid 2011; Schmid et al. 2009, 2011). It can even collect thin-walled particles without breaking (Feng et al. 2011).

After completion of the nano spray drying process, the dried powder particles are gently collected from the inner 


\section{Heater made of porous metal foam for laminarization of the drying gas flow}
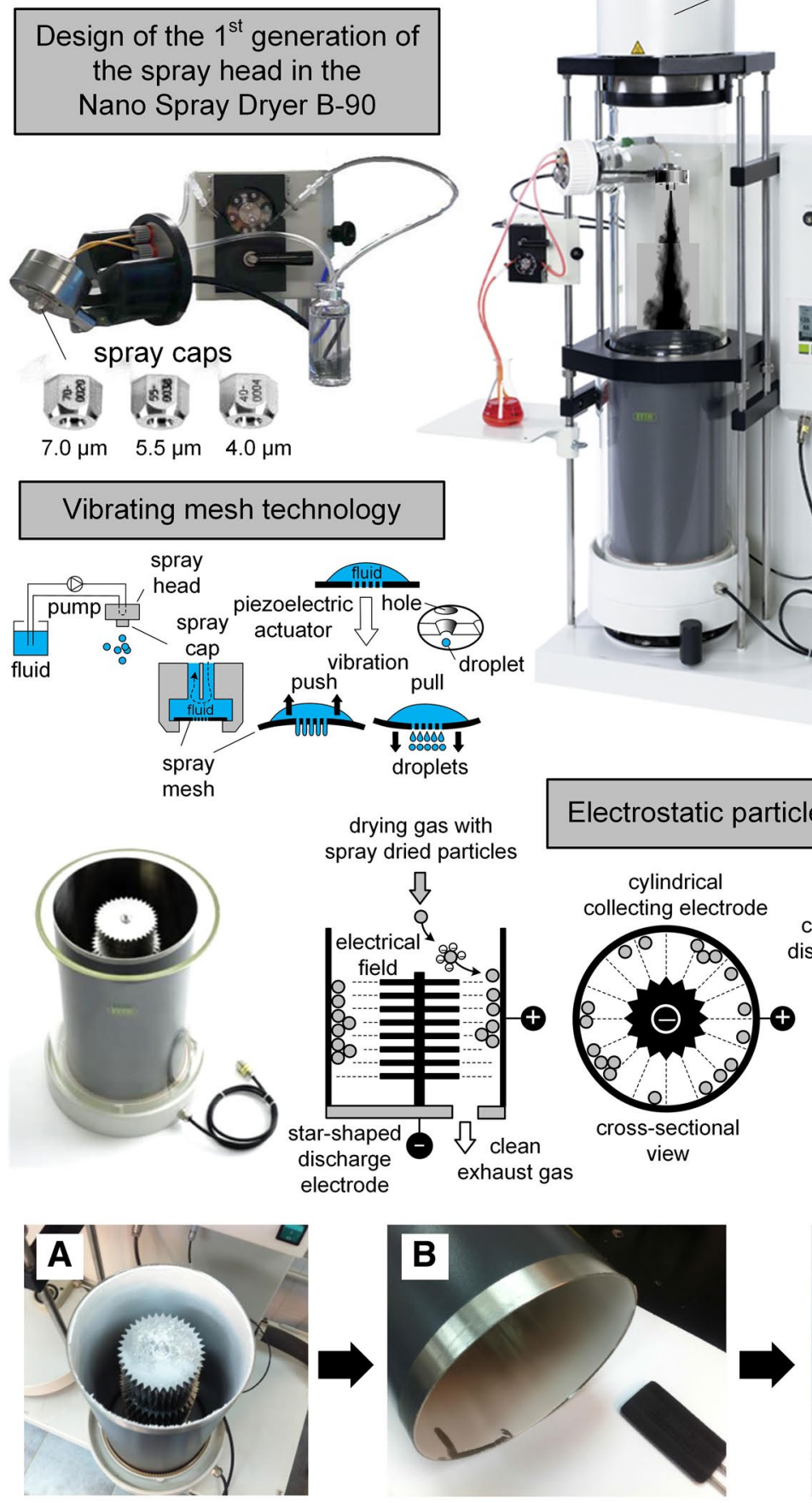
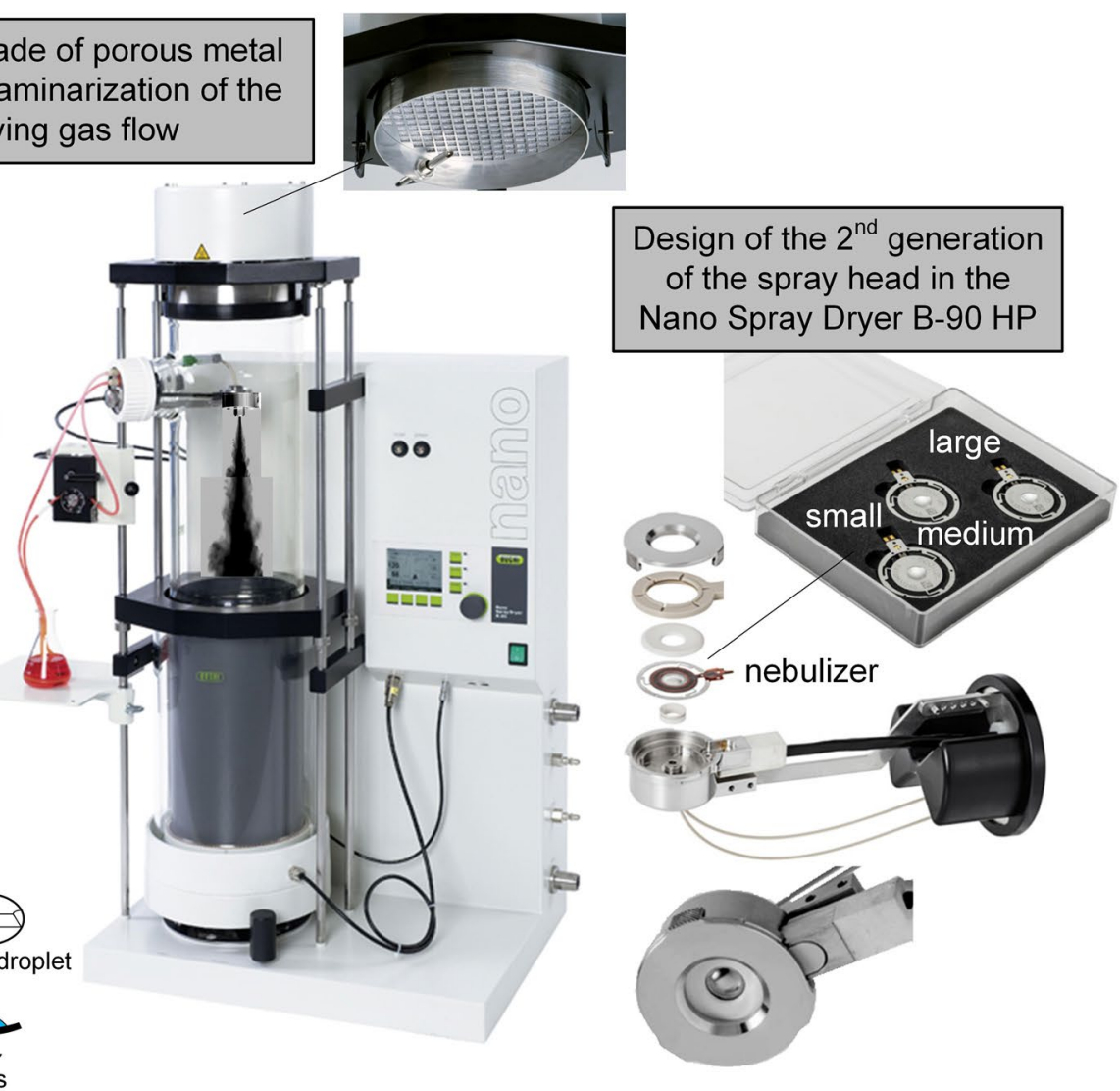

Electrostatic particle collection
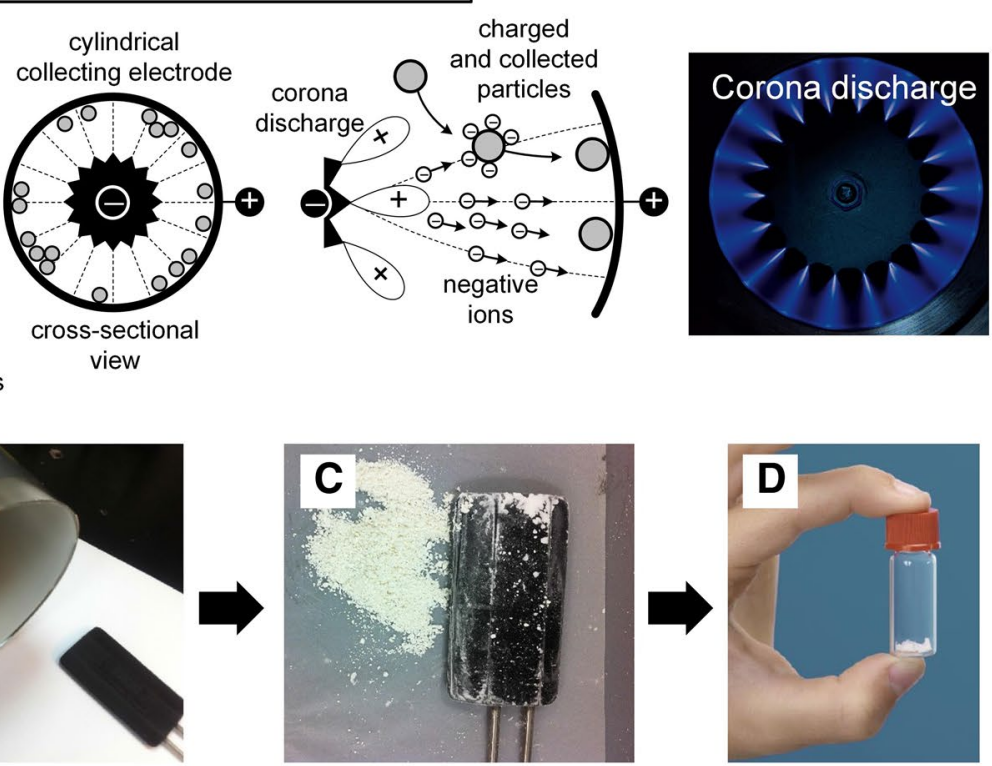

Fig. 2 Nano Spray Dryer B-90 (short set-up) with the 1st and 2nd generation of vibrating mesh technology for spray generation, the electrostatic particle collector, and the heater made of porous metal foam for gas laminarization (pictures courtesy of Büchi Labortechnik
AG). Particle collection process: A dried particles deposited on the collection cyclinder (minor losses on the star-electrode in the center), B collection cylinder with particle scraper, $\mathbf{C}$ manually recovered powder on collecting paper, $\mathbf{D}$ powder filled in air-tight glass vial 


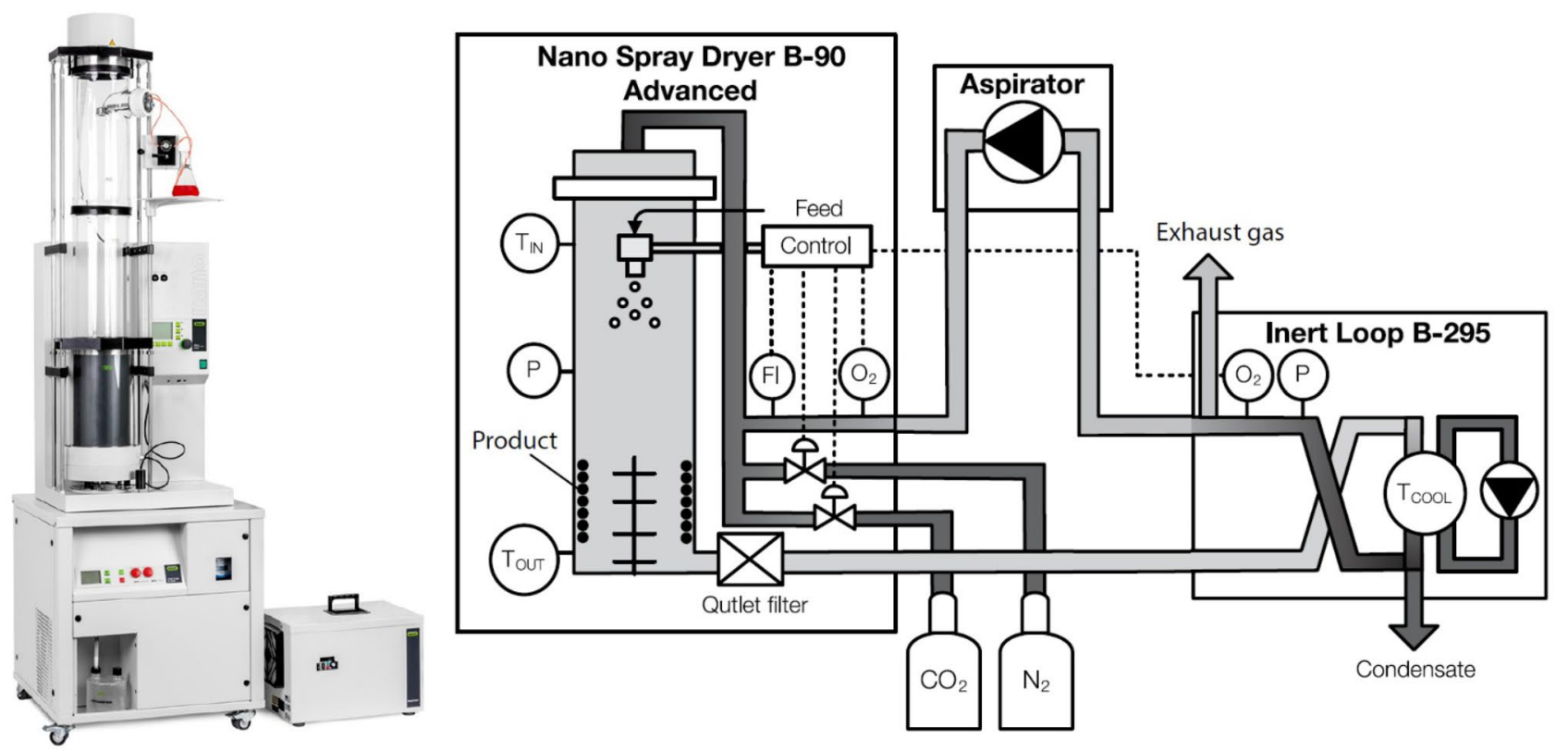

Fig. 3 Set-up and schematic digramm of the Nano Spray Dryer B-90 with the Inert Loop B-295 and aspirator for closed mode operation with inert gas $\left(\mathrm{N}_{2} / \mathrm{CO}_{2}\right)$ for drying organic solvents Adapted from Büchi Labortechnik (2017)

surface of the collecting electrode cylinder with a particle scraper (see procedure in Fig. 2). The particles are then filled into airtight glass vials and stored under controlled and dry conditions (e.g. in a desiccator over silica gel at room temperature) until further usage and examination. When manually collecting the powder with a scraper, minimal losses may occur reducing the overall yield.

\section{Influence of process parameters on powder properties}

Table 2 provides an overview of the main process parameters for nano spray drying and their influence on the final powder properties. The thickness of each arrow illustrates the strength of the relationship.
There are several process parameters that can be varied to optimize the yield, drug loading, encapsulation efficiency, particle size, drug release profile, stability, and morphology (Arpagaus 2018a, b, c; Arpagaus et al. 2013, 2017, 2018). Depending on the application, an optimized set of process parameters is found. The optimization is usually done by trial and error. However, design of experiment (DOE) studies are helpful in optimizing the nano spray drying process (Arpagaus et al. 2017; Draheim et al. 2015; Schafroth et al. 2012).

As shown in Table 2, the key parameters controlling the final spray dried particle size are the spray mesh size and the solid concentration. Obviously, smaller droplets are favored by a smaller spray mesh. The submicron particle size is typically reached when using a $4.0 \mu \mathrm{m}$ spray mesh and diluted solutions of about 0.1 to $1 \%(\mathrm{w} / \mathrm{v})$, as demonstrated

Table 2 Influence of the main process parameters in nano spray drying ( $/$ strong increasing/decreasing influence, decreasing influence, - minimal or no influence) Adapted from Arpagaus et al. (2017)

\begin{tabular}{|c|c|c|c|c|c|c|c|}
\hline Process parameter & $\begin{array}{c}\text { Outlet } \\
\text { temperature }\end{array}$ & $\begin{array}{l}\text { Droplet } \\
\text { size }\end{array}$ & $\begin{array}{c}\text { Particle } \\
\text { size }\end{array}$ & $\begin{array}{l}\text { Feed } \\
\text { rate }\end{array}$ & $\begin{array}{c}\text { Moisture } \\
\text { content }\end{array}$ & Yield & Stability \\
\hline Drying gas flow rate $\uparrow$ & 순 & - & - & - & 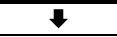 & - & - \\
\hline Drying gas humidity $\uparrow$ & $\uparrow$ & - & - & - & 수 & $\downarrow$ & - \\
\hline Inlet temperature $\uparrow$ & 1 & - & $\uparrow$ & - & $\downarrow$ & $\uparrow$ & 7 \\
\hline Spray mesh size $\uparrow$ & $\downarrow$ & 1) & 1) & 1) & - & - & $\uparrow$ \\
\hline Spray frequency $\uparrow$ & 7 & $\uparrow$ & $\uparrow$ & 1 & $\uparrow$ & - & 7 \\
\hline Circulation pump rate $\uparrow$ & - & $\uparrow$ & $\uparrow$ & $\uparrow$ & - & - & $\uparrow$ \\
\hline Solid concentration (viscosity) $\uparrow$ & $\uparrow$ & - & 1) & 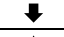 & $\downarrow$ & $\uparrow$ & - \\
\hline Surfactant/stabilizer in feed $\uparrow$ & - & $\downarrow$ & $\downarrow$ & $\uparrow$ & - & $\uparrow$ & -1 \\
\hline Organic solvent instead of water & 1 & $\downarrow$ & $\downarrow$ & $\uparrow$ & 7 & $\uparrow$ & - \\
\hline
\end{tabular}

Nano spray drying process parameter table ( $/$ strong increasing/decreasing influence, $\uparrow / \downarrow$ weak increasing/decreasing influence, - minimal or no influence) 
in several studies (Amsalem et al. 2017; Anzar et al. 2018; Beck-Broichsitter et al. 2012, 2015a; Bege et al. 2013; Panda et al. 2016; Schafroth et al. 2012). The organic solvents typically used in the nano spray drying of PLA/PLGA biopolymers are mainly:

- dichloromethane (DCM) (Beck-Broichsitter et al. 2012; Bege et al. 2013; Dahili et al. 2017; Dahili and Feczkó 2015; Draheim et al. 2015; Panda et al. 2016; Schafroth et al. 2012)

- acetone (Beck-Broichsitter et al. 2015b; Draheim et al. 2015),

- acetonitrile (Amsalem et al. 2017),

- ethyl acetate (Draheim et al. 2015), and

- mixtures of DCM/ethanol (70/30, v/v) (Schafroth et al. 2012).

The selection of the organic solvent is based on the solubilization of the drug and the encapsulating biopolymer. DCM (boiling point of $40{ }^{\circ} \mathrm{C}$ ) and acetone $\left(56^{\circ} \mathrm{C}\right)$ enable low drying temperatures which leads to fast drying and prevents particles from sticking to the walls or agglomerating. An optimum inlet drying gas temperature for PLGA dissolved in DCM was reported to be in the range of 29 to $32{ }^{\circ} \mathrm{C}$ (Schafroth et al. 2012).

As shown schematically in Fig. 4A, the droplet temperature in a nano spray dryer rises initially to the saturated wetbulb surface temperature, remains constant during evaporation, and approaches the temperature of the surrounding gas at the dryer outlet (Arpagaus 2018a; Arpagaus et al. 2017).

The outlet temperature $\left(T_{\text {out }}\right)$ of the drying gas is directly related to the set inlet temperature $\left(T_{i n}\right)$, the drying gas flow rate, the sample concentration and the fluid feed rate (Büchi Labortechnik 2011). Changes in any of these parameters will either increase or decrease the outlet gas temperature. A lower drying gas flow rate leads to a lower outlet temperature. A smaller feed rate increases the outlet temperature because less fluid is evaporated over the same period of time. Generally, a higher solid concentration results in a lower feed rate (Beck-Broichsitter et al. 2015b; Schmid 2011). A lower relative spray rate intensity reduces the feed rate almost linearly (Beck-Broichsitter et al. 2015b).

Figure 4B shows a linear correlation between the inlet and the outlet temperature for DCM solution in the Nano Spray Dryer B-90 (Büchi Labortechnik AG 2011). The outlet temperature is between 21 and $35{ }^{\circ} \mathrm{C}$ and thus below the glass transition temperature of certain PLGA polymers of about 37 to $54{ }^{\circ} \mathrm{C}$ (Schafroth et al. 2012). This makes nano spray drying a suitable process for heat-sensitive pharmaceuticals (Amsalem et al. 2017; Heng et al. 2011). A compromise needs to be found between feed rate, solid concentration, and particle size. The feed rate increases with the spray mesh size and the setting of the relative spray frequency (Fig. 4C).
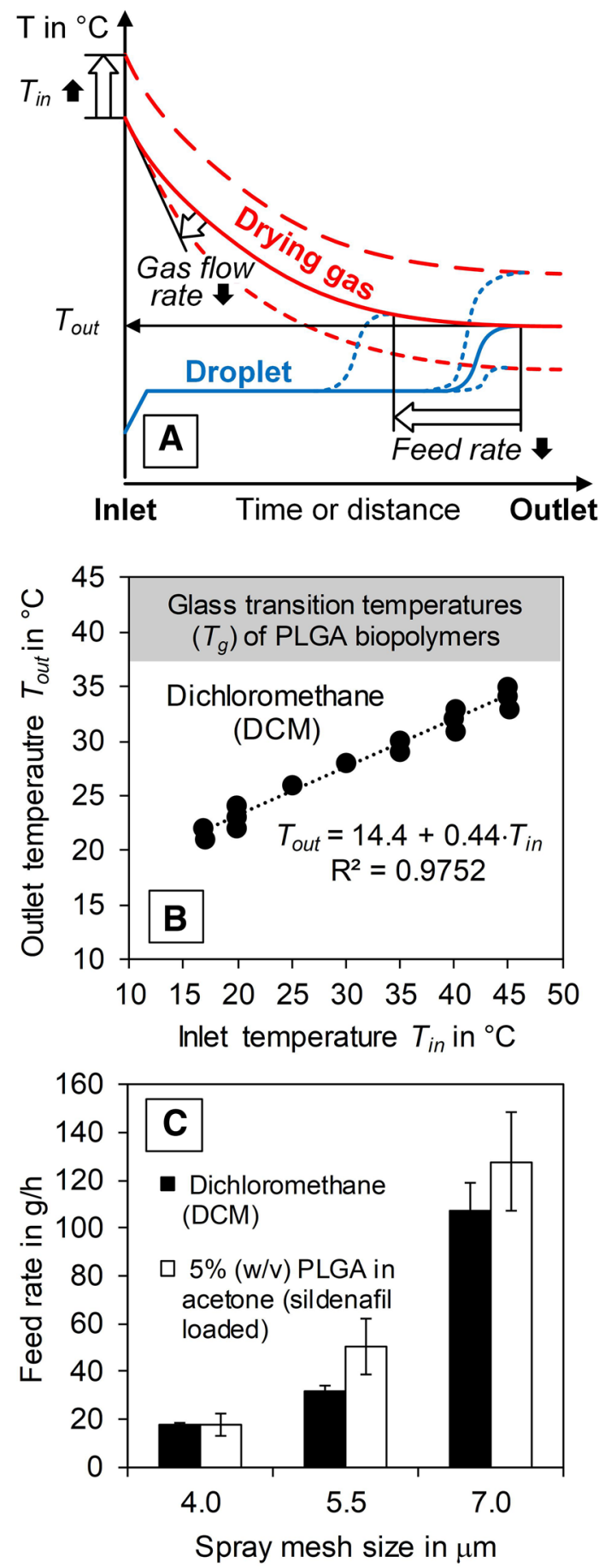

Fig. 4 A Typical temperature profile of the drying gas and the droplets during nano spray drying. The influence of drying gas temperature, gas throughput and feed on the droplet temperature is illustrated schematically (Arpagaus 2018a; Arpagaus et al. 2017). B Linear correlation between inlet $\left(T_{\text {in }}\right)$ and outlet $\left(T_{\text {out }}\right)$ drying gas temperature in the Nano Spray Dryer B-90 when spraying dichloromethane (DCM), i.e. $T_{\text {out }}=14.3+0.333 T_{\text {in }}$ (in ${ }^{\circ} \mathrm{C}$ ) (Büchi Labortechnik 2011). $\mathbf{C}$ Feed rate as a function of the spray mesh size: (black bars) pure DCM (Büchi Labortechnik 2011) and (white bars) 5\% (w/v) PLGA solution with sildenafil (10\% of polymer mass) in acetone (Beck-Broichsitter et al. 2015b) 
For pure DCM, the feed rates are in the ranges of 18,32 and $107 \mathrm{~g} / \mathrm{h}$ for a $4.0,5.5$, and $7.0 \mu \mathrm{m}$ spray mesh, respectively (Büchi Labortechnik AG 2010). A significant increase in the flow rate from 18 to $128 \mathrm{~g} / \mathrm{h}$ with a spray mesh size of 4.0 and $7.0 \mu \mathrm{m}$ was also observed with a 5\% (w/v) PLGA solution in acetone (Beck-Broichsitter et al. 2015b).

\section{Particle morphology}

Figure 5 shows some SEM images of representative nano spray dried PLA/PLGA particles. In general, the slow and gentle drying in a nano spray dryer yields almost spherical and compact particles. In general a dilution of the solution leads to an end product with a smaller particle size. Typically, the solids concentrations were in the range of 0.1 to $1 \%(\mathrm{w} / \mathrm{v})$. Micrometer-sized composite particles of PLGA nanoparticles are another interesting particle morphology for drug delivery applications. More details on the nano spray drying conditions are given in the next section.

After nano spray drying, the activity of the encapsulated product is preserved if the powder is stored under controlled conditions and if a stabiliser is added into the feed formulation. Most nano spray dried powders are amorphous due to the short drying time. To prevent recrystallization of amorphous drugs, the powders are stored under dry conditions. An option to minimize the potential of activity loss during the nano spray drying process is to cool the feed vessel in ice bath $\left(\geq 4{ }^{\circ} \mathrm{C}\right.$ ) (Amsalem et al. 2017; Schoubben et al. 2013; Torge et al. 2017) or to use a larger spray mesh (e.g. $7.0 \mu \mathrm{m}$ ) to reduce the mechanical shear of atomization (Abdel-Mageed et al. 2019; Bürki et al. 2011). With highly diluted solutions containing 0.1 to $1 \%(\mathrm{w} / \mathrm{v})$ solids concentrations, finest solid particles down to $100 \mathrm{~nm}$ can be obtained by nano spray drying.

\section{Analytical methods}

Commonly applied analytical methods to characterize the nano spray dried powders are scanning electron microscopy (SEM) to determine particle size and morphology, laser diffraction to measure particle size (dynamic light scattering), and X-ray diffraction (XRD) or differential scanning calorimetry (DSC) to identify the amorphous and crystalline state. Drug release studies are performed e.g. by highperformance liquid chromatography with UV detection. The mathematical models for controlled release of substances are, for example, summarized in (Arpagaus et al. 2018). The release of a bioactive compound in an ideal system may follow zero (constant release rate, pure material, no encapsulation), half (matrix particles) or first (core is a solution) order kinetics. The equations of Higuchi or Korsmeyer-Peppas are generally used to characterize the kinetic mechanism of controlled release of substances.

\section{Applications of nano spray dried PLA/PLGA biopolymers}

Since its market launch in 2009, the Nano Spray Dryer B-90 has been used in the laboratory mainly in the research fields of drug delivery, bioactive food ingredients, and material science to convert various liquid feeds into dry powder (Arpagaus 2011, 2012, 2018b, c, d). Its range of applications is constantly evolving.

Table 3 shows a number of published studies on encapsulation of active ingredients in PLA and PLGA biopolymers by nano spray drying. The experimental process parameters can serve as a first reference for the production of submicron powders and the application of a Nano Spray Dryer B-90 with similar substances and solvents.

The research activities are focused on the treatment of:

- inflammation by dexamethasone (Schafroth et al. 2012),

- transplants rejection reactions and dermatitis by cyclosporin (Schafroth et al. 2012),

- pulmonary arterial hypertension with sildenafil (BeckBroichsitter et al. 2012, 2015a, b),

- antipsychotic diseases like schizophrenia by clozapine and risperidone (Panda et al. 2016),

- breast cancer by simvastatin (Anzar et al. 2018),

- genetic disorders and silencing of transcription during gene expression by siRNA-loaded human serum albumin nanoparticles (Amsalem et al. 2017), and

- orcerebral vasospasm (e.g. narrowing of blood vessels in the brain) by nimodipine (Bege et al. 2013).

Schafroth et al. (2010, 2012) optimized the processing parameters of nano spray drying to encapsulate the poorly soluble cyclosporine A (an immunosuppressive drug) and dexamethasone (an anti-inflammatory steroid drug) in biodegradable PLGA nanoparticles with different PLGA grades (50:50 and 85:15 lactide:glycolide ratio) and molecular weights ( $15 \mathrm{kDa}, 40$ to $75 \mathrm{kDa})$. The drugs and the PLGA polymers were dissolved in DCM/ ethanol $(70: 30 \mathrm{v} / \mathrm{v})$ organic mixture. The particles were about 0.9 to $2.2 \mu \mathrm{m}$ in size and had a spherical shape, narrow size distribution and highly porous surface structure (Fig. 5A-C). XRD analysis showed that cyclosporine was present in an amorphous form in the PLGA particles, while dexamethasone was in crystalline state. The yield ranged from about 50 to $55 \%$. The drug encapsulation efficiency for both drugs was between 80 to $95 \%$ (Schafroth 2010). The inlet temperature was kept below $32{ }^{\circ} \mathrm{C}$ for all drugs in order not to reach the Tg of PLGA. In vitro studies demonstrated sustained release profiles for the drugs from 15 to 30 days depending on the PLGA grade. 

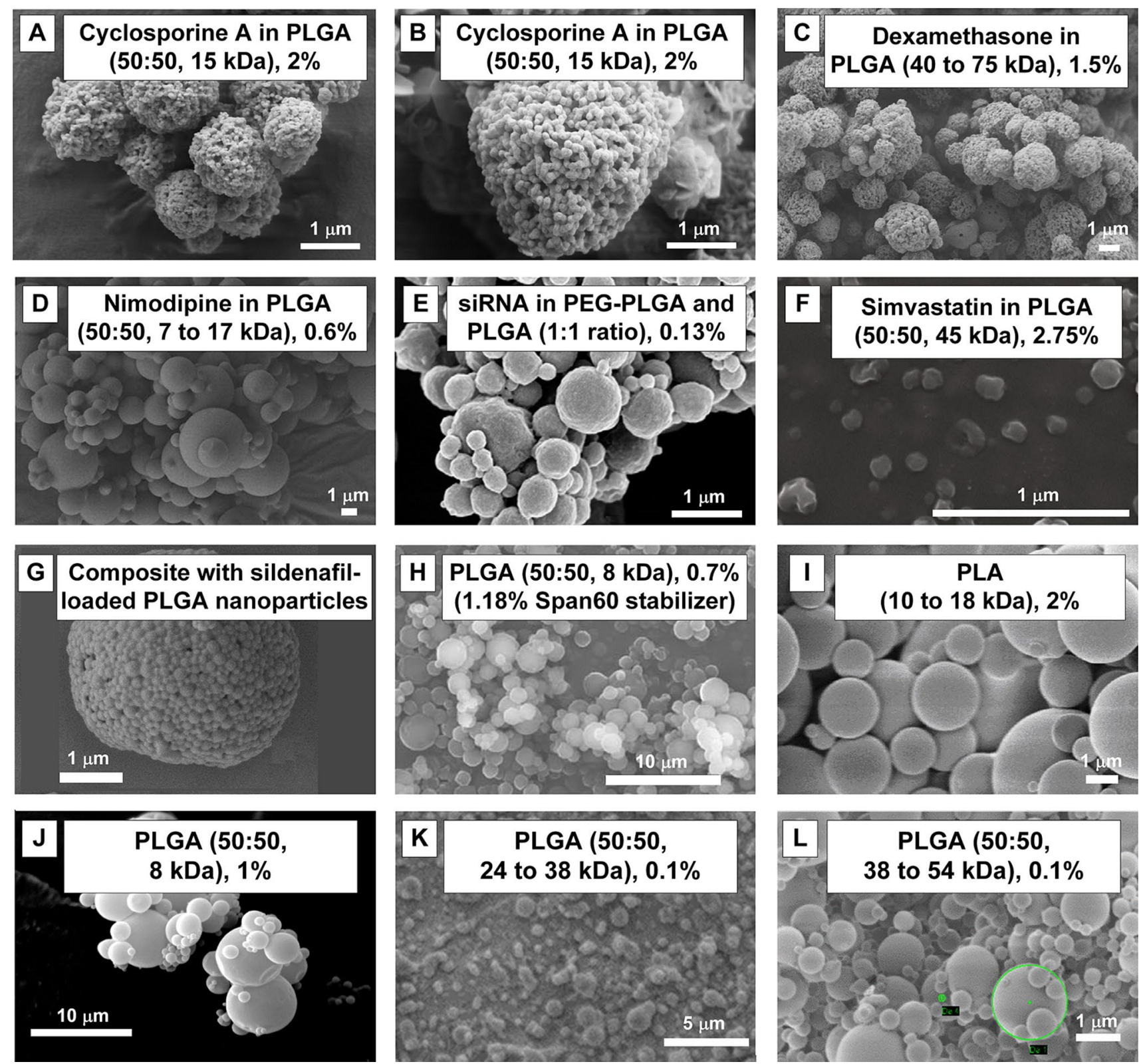

Fig. 5 SEM pictures of nano spray dried particles (reprinted with permission). A and B Cyclosporine-loaded PLGA particles (50:50, $15 \mathrm{kDa})(2 \% \mathrm{w} / \mathrm{v}$ dissolved in DCM/ethanol (70:30) and nano spray dried at $29{ }^{\circ} \mathrm{C}$ ) (Schafroth 2010; Schafroth et al. 2012). C Dexamethasone-loaded PLGA particles (50:50, 40 to $75 \mathrm{kDa}, 1.5 \% \mathrm{w} / \mathrm{v}$ in DCM/ethanol (70:30) and nano spray dried with $5.5 \mu \mathrm{m}$ spray mesh at $50 \%$ spray rate) for the treatment of inflammation (Schafroth 2010; Schafroth et al. 2012). D Nimodipine-loaded PLGA particles (50:50, 7 to $17 \mathrm{kDa}, 0.6 \% \mathrm{w} / \mathrm{v}$ in $\mathrm{DCM})$ for suspension in fibrin sealant as an in situ forming depot system for treatments related to brain surgery (Bege et al. 2013). E Nano-in-nanoparticles made of PEGPLGA (100 kDa) and PLGA (100 kDa) loaded with human serum albumin primary nanoparticles containing siRNA (Amsalem et al. 2017). F Simvastatin-loaded PLGA submicron particles for the treatment of breast cancer (Anzar et al. 2018). G Composite particle fab- ricated from aqueous suspension containing sildenafil-loaded PLGA nanoparticles (Beck-Broichsitter et al. 2012). H Round and regular shaped PLGA $(50: 50,8 \mathrm{kDa})$ particles prepared from $0.7 \%(\mathrm{w} / \mathrm{v})$ acetone solution with $1.18 \%(\mathrm{w} / \mathrm{v})$ of $\operatorname{Span}^{\circledR} 60$ as stabilizer (Draheim et al. 2015). I Sperical PLA (10 to $18 \mathrm{kDa}$ ) particles from a $2 \%$ $(\mathrm{w} / \mathrm{v})$ solution in DCM with a $4.0 \mu \mathrm{m}$ spray mesh (Büchi Labortechnik AG 2009). J PLGA (50:50, $8 \mathrm{kDa})$ carrier particles $(1 \% \mathrm{w} / \mathrm{v}$, $5.5 \mu \mathrm{m}$ spray mesh) for the immobilization of horeradish peroxidase enzyme in waste-water treatment (Dahili and Feczkó 2015). K Nano spray dried PLGA (50:50, 24 to $38 \mathrm{kDa}$ ) particles for surface coating of small medical implants (Baghdan et al. 2018). L Submicron PLGA (50:50, 38 to $54 \mathrm{kDa})$ spheres obtained from $0.1 \%(\mathrm{w} / \mathrm{v})$ solution in acetonitrile/water (95:5) and 0.005\% sodium acetate (Büchi Labortechnik 2017) 


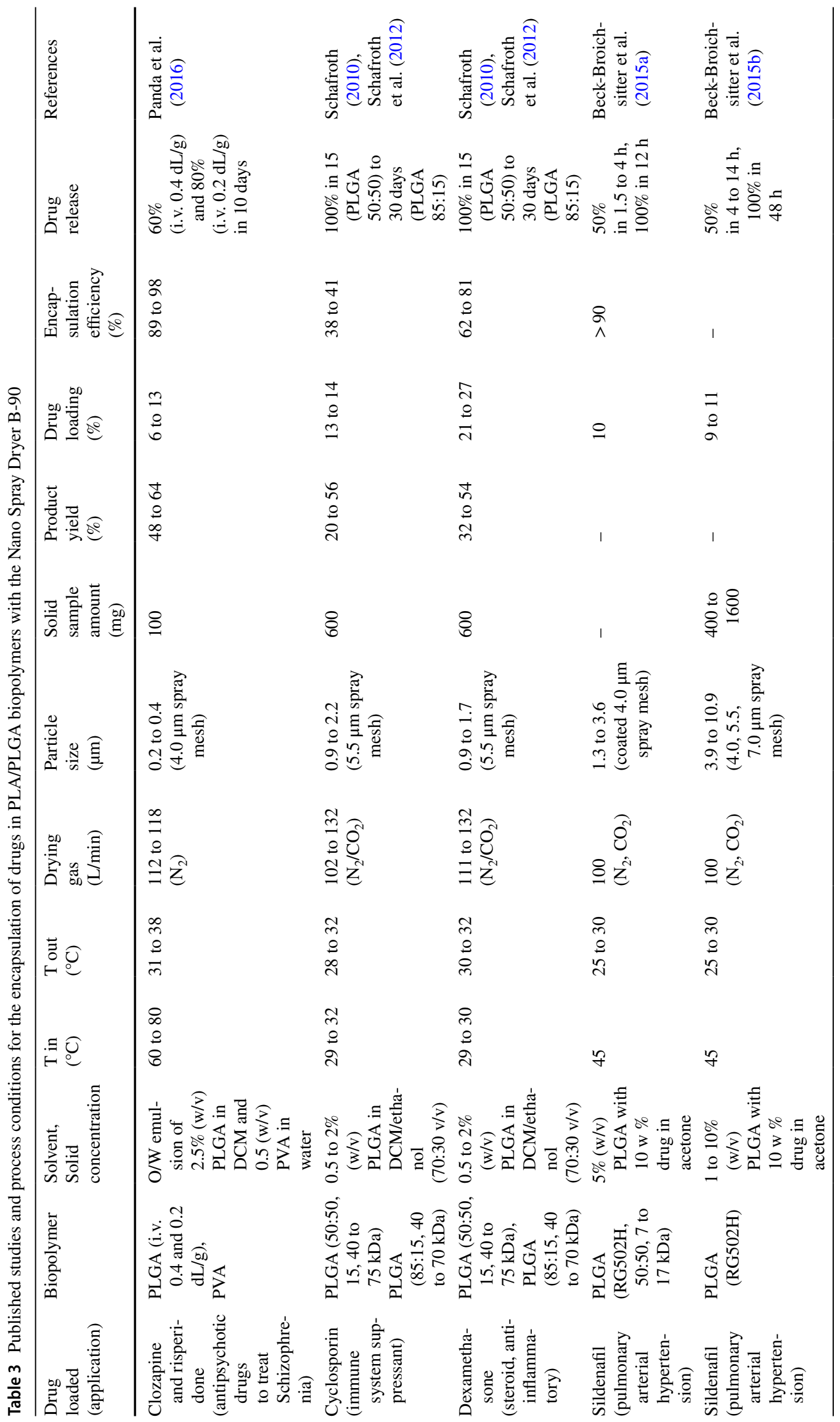




\begin{tabular}{|c|c|c|c|}
\hline 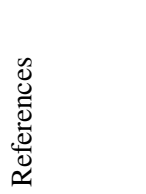 & 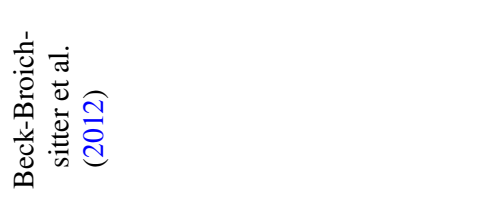 & 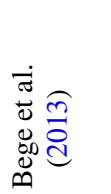 & 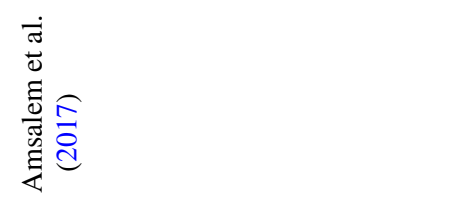 \\
\hline 占竞 & 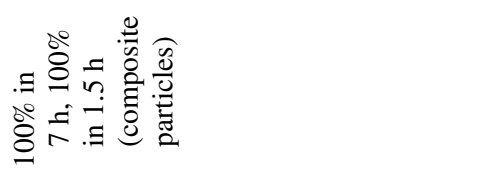 & $\begin{array}{l}\stackrel{5}{a} \\
\stackrel{a}{\circ} \\
\text { ă }\end{array}$ & 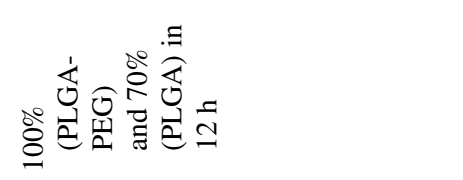 \\
\hline 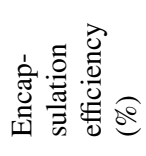 & I & $\begin{array}{l}\stackrel{\infty}{a} \\
\stackrel{0}{\sigma} \\
\sigma\end{array}$ & 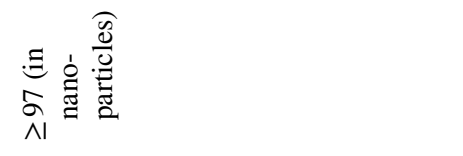 \\
\hline 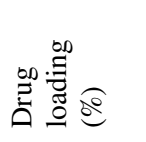 & 0 & $\begin{array}{l}\stackrel{+}{+} \\
\stackrel{9}{0} \\
\stackrel{0}{=}\end{array}$ & 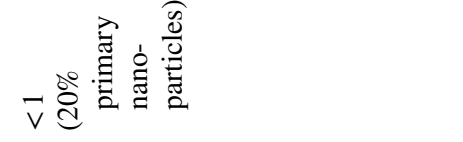 \\
\hline 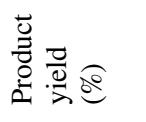 & 1 & 1 & $\begin{array}{l}8 \\
8 \\
0 \\
0 \\
0\end{array}$ \\
\hline 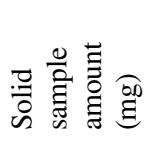 & 1 & \&্ল & $\begin{array}{l}8 \\
\stackrel{2}{2} \\
\stackrel{0}{0} \\
\stackrel{1}{2}\end{array}$ \\
\hline 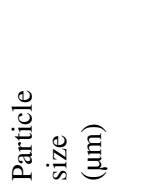 & 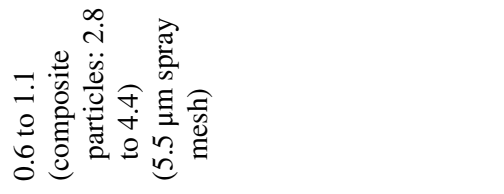 & 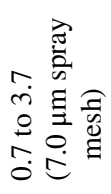 & $\begin{array}{l} \\
\infty \\
\infty \\
0 \\
0 \\
0 \\
0 \\
0 \\
0 \\
0 \\
0 \\
0\end{array}$ \\
\hline 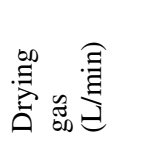 & $\nsubseteq$ & Iิ & 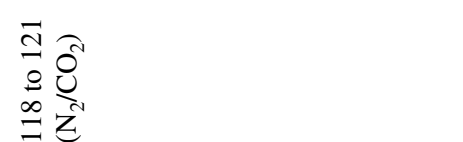 \\
\hline 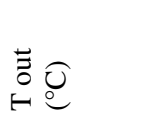 & $\begin{array}{l}0 \\
\text { c } \\
0 \\
0 \\
0\end{array}$ & 1 & $\stackrel{\infty}{m}$ \\
\hline$: \Xi 0$ & $\begin{array}{l}0 \\
n \\
0 \\
0 \\
0\end{array}$ & rq & in \\
\hline 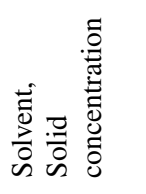 & 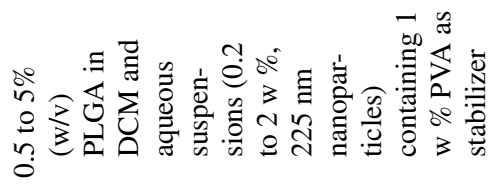 & 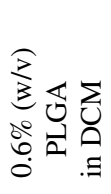 & 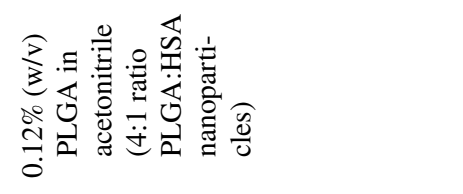 \\
\hline 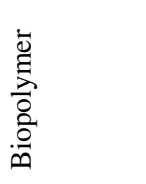 & 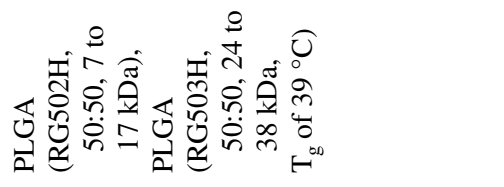 & 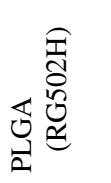 & 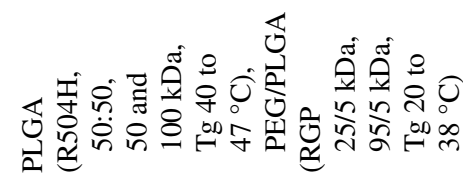 \\
\hline 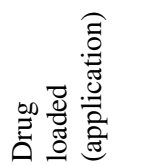 & 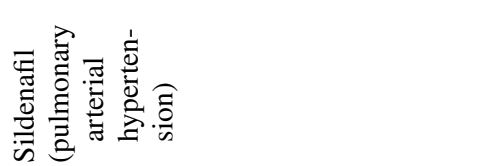 & 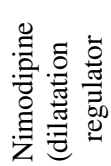 & 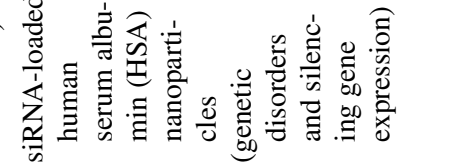 \\
\hline
\end{tabular}




\begin{tabular}{|c|c|c|c|c|c|}
\hline 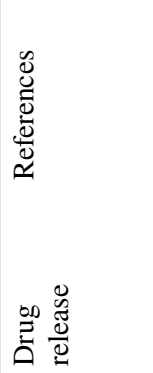 & 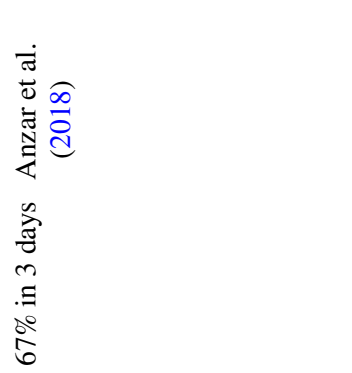 & 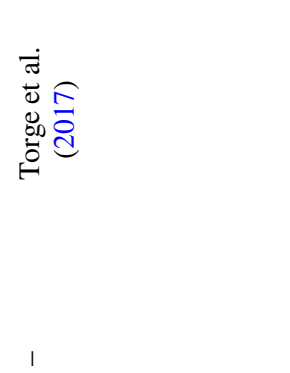 & 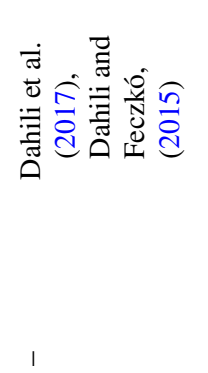 & 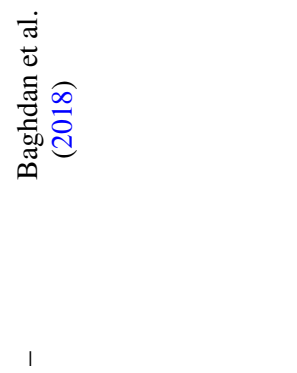 & 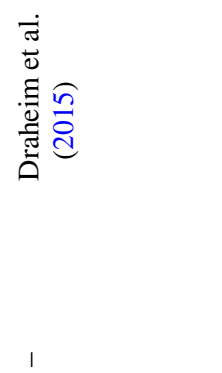 \\
\hline 它.泀 & 8 & । & 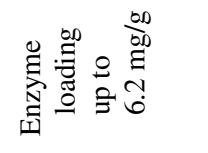 & 1 & । \\
\hline$\stackrel{b 0}{:}$ & $n$ & 1 & 1 & 1 & 1 \\
\hline 咅 & 1 & 1 & 1 & 1 & $\begin{array}{l}\hat{\beta} \\
\mathrm{V} 1\end{array}$ \\
\hline 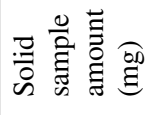 & $\cong$ & \& & 1 & 1 & $\begin{array}{l}9 \\
\stackrel{0}{0} \\
\stackrel{n}{m}\end{array}$ \\
\hline 总 & 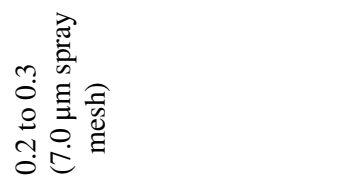 & 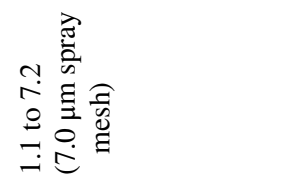 & 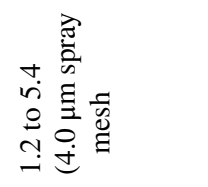 & 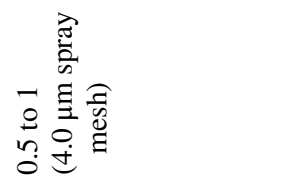 & 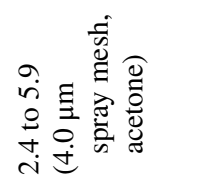 \\
\hline 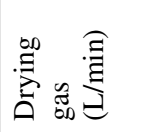 & 1 & 肙 & 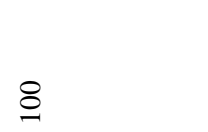 & 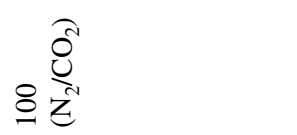 & 总 \\
\hline 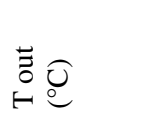 & 1 & $\begin{array}{c}\text { ले } \\
\stackrel{0}{N} \\
\text { లn }\end{array}$ & 1 & $\begin{array}{l}\dot{1} \\
\text { m } \\
\stackrel{0}{\infty} \\
\infty \\
i\end{array}$ & $\begin{array}{l}0 \\
\text { cn } \\
0 \\
0 \\
\text { ì }\end{array}$ \\
\hline $\begin{array}{l}: \equiv 0 \\
\forall 0\end{array}$ & 1 & $\infty$ & 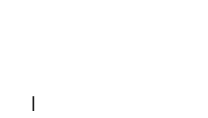 & $\approx n$ & $\begin{array}{l}8 \\
8 \\
2 \\
0\end{array}$ \\
\hline 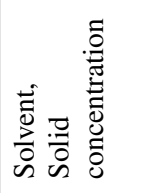 & 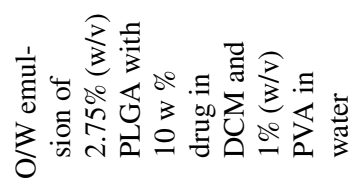 & 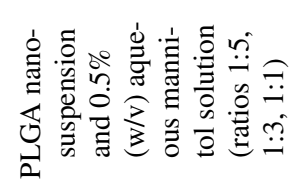 & 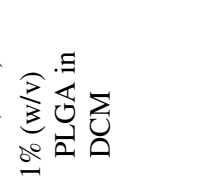 & 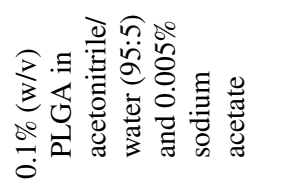 & 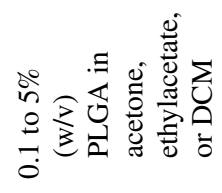 \\
\hline 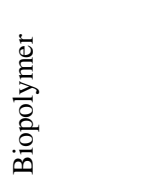 & 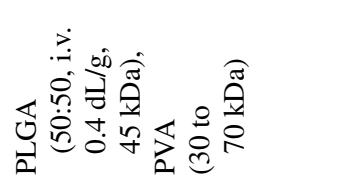 & 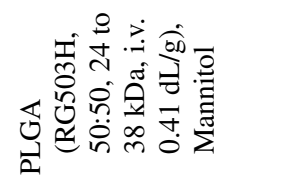 & 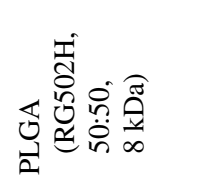 & 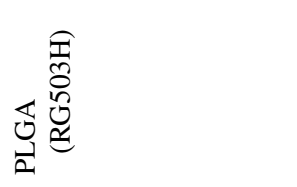 & 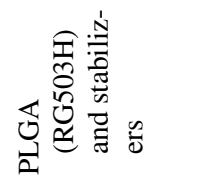 \\
\hline 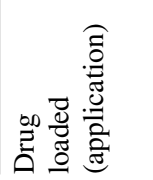 & 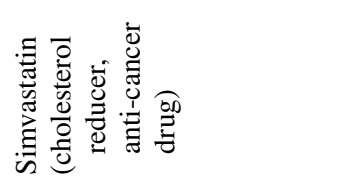 & 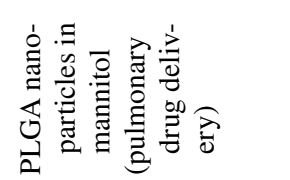 & 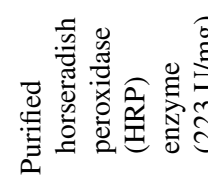 & 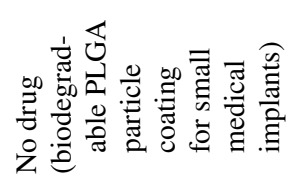 & 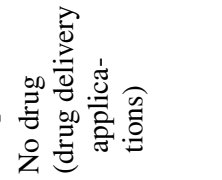 \\
\hline
\end{tabular}




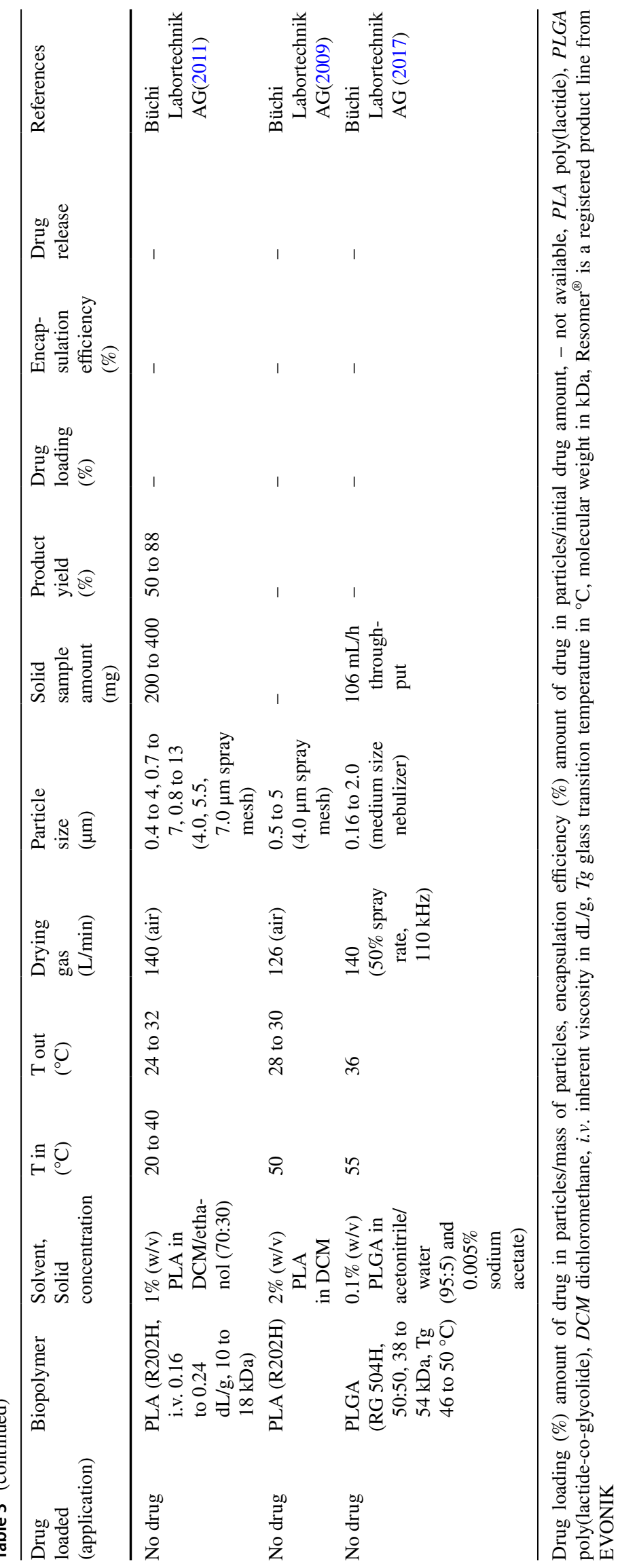


Lower release rates were obtained with PLGA 85:15 compared to 50:50 lactide/glycolide ratios. Faster release rates were observed for low molecular weight PLGA (5 kDa) compared to higher molecular weights (40 to $70 \mathrm{kDa}$ ) (Schafroth et al. 2012).

Beck-Broichsitter et al. (2012) prepared two types of powder formulations using sildenafil as model drug for pulmonary administration. In first the case, 567 to $1129 \mathrm{~nm}$ particles were produced by nano spray drying of organic solutions of PLGA (50:50, 7 to $17 \mathrm{kDa}$ ) and drug. In the second case, composite microparticles of about 2.8 to $4.4 \mu \mathrm{m}$ were obtained from nano spray drying an aqueous nanosuspension of drug-loaded PLGA nanoparticles of around $225 \mathrm{~nm}$ prepared by solvent evaporation method. As shown in Fig. 6, the surface of the nanoparticles prepared from the polymer solution was smooth while the surface of the composite microparticles was decorated by individual nanoparticles and thus exhibited a larger specific surface area.

After redispersion of the composite particles there where no signs of nanoparticle aggregation. The aerodynamic properties of both particle types revealed aerosol particle sizes suitable for deep lung deposition $(\leq 4 \mu \mathrm{m})$. While the entrapped drug was released within about $1.5 \mathrm{~h}$ from the composite particles, a sustained drug release over about $7 \mathrm{~h}$ was observed for nanoparticles prepared from PLGA-drug solution.

In further studies, Beck-Broichsitter et al. (2015a, b) demonstrated that smaller PLGA particles generated with smaller spray meshes exhibited a faster release of the active compound, due to the larger exposed surface area. A further reduction of the vibrating mesh opening diameter from 4.0 to about $2.0 \mu \mathrm{m}$ by applying a uniform polymer coating generated by chemical vapor deposition of poly(p-xylylene) resulted in smaller acetone droplets (about $4 \mu \mathrm{m}$ compared to $10 \mu \mathrm{m}$ ), smaller dried particles, narrower size distribution, and higher release rates similar to those of composite particles (Beck-Broichsitter et al. 2015a).

In another application, Bege et al. (2013) encapsulated nimodipine in PLGA particles by nano spray drying. Nimodipine is a substance that regulates the dilatation of blood vessels, particularly the cerebral vasculature in the brain. Originally it was developed for the treatment of high blood pressure. The nano spray dried particles ranged from 1.9 to $2.4 \mu \mathrm{m}$ (Fig. 5D) and were suspended in a fibrin sealant as an in situ depot system for treatments related to brain surgery. The fibrin glue is biodegradable and stable in the cerebrospinal fluid inside the brain and the spine. Figure 7 illustrates the preparation procedure to incorporate nimodipine-loaded biodegradable PLGA particles into fibrin sealant depot system.

The PLGA particles were also colored with encapsulated fluorescent coumarin dye to visualize the homogeneity of the suspended drug particles in the adhesive. Nimodipine loads of 10 to $40 \%$ and high encapsulation efficiency of 93 to $98 \%$ could be achieved, which make the depot forming system promising for the local treatment of cerebral vasospasm after a subarachnoid haemorrhage (bleeding).

Panda et al. (2016) co-entrapped the antipsychotic drugs clozapine and risperidone in about 235 to $260 \mathrm{~nm}$ PLGA nanoparticles by nano spray drying and observed sustained drug release profiles in vitro over several days. The drugs were evenly dispersed within the PLGA particles without any crystalline content. The release kinetics of active compounds encapsulated in PLGA polymers with a low molecular weight were faster (about $80 \%$ release in 10 days) compared to those with a high molecular weight (about 60\%

\section{Nano Spray Drying}
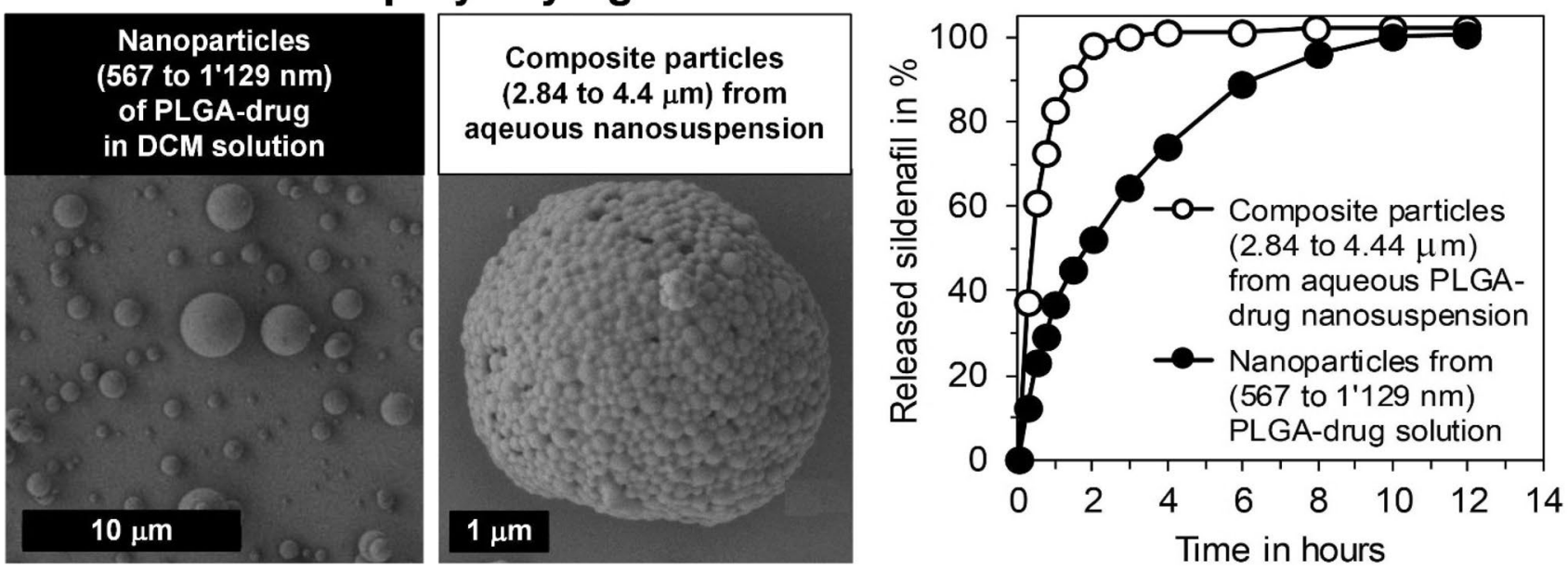

Fig. 6 In vitro sildenafil release profiles from nano spray dried composite and PLGA (50:50, 7 to $17 \mathrm{kDa})$ nanoparticles Adapted from BeckBroichsitter et al. (2012) 


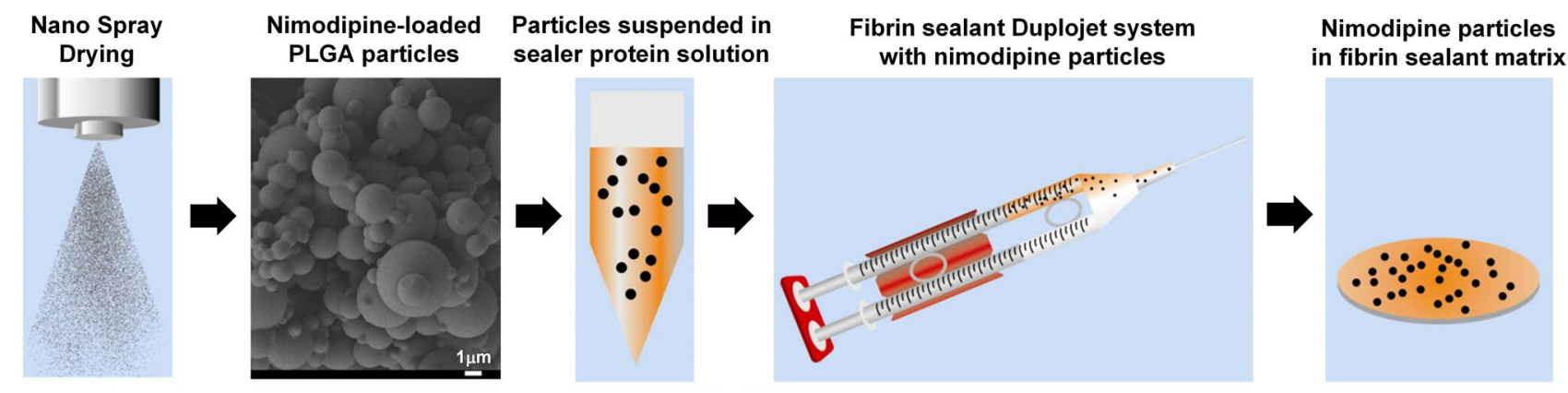

Fig. 7 Preparation procedure to incorporate nano spray dried nimodipine-loaded biodegradable PLGA particles into fibrin sealant depot sytem for treatments related to brain surgery Adapted from Bege et al. (2013)

release in 10 days), due to the higher hydrolysis and degradation rate. The prepared particles could be used as an injectable formulation to cross the blood-brain barrier for the treatment of psychotic disorders, such as Schizophrenia.

Amsalem et al. (2017) loaded primary human serum albumin (HSA) nanoparticles (about $100 \mathrm{~nm}$ ) with small interfering RNAs (siRNA) and encapsulated the suspension in PLGA and PEG/PLGA biopolymers by nano spray drying. PLGA and PEG/PLGA (mixing ratio of 1:1) with high molecular weights of $100 \mathrm{kDa}$ and glass transition temperatures of $42.8^{\circ} \mathrm{C}$ were applied. By using acetonitrile (boiling point of $82{ }^{\circ} \mathrm{C}$ ) with a total solids content of $0.13 \%(\mathrm{w} / \mathrm{v})$ and an inlet temperature of $50{ }^{\circ} \mathrm{C}$ and outlet temperature of $38{ }^{\circ} \mathrm{C}$, a reproducible nano spray drying process was achieved avoiding thermal damage to the heat-sensitive siRNA. The produced solid nano-in-nanoparticles, termed double nanocarriers (DNC), had a mean size of about 580 to $770 \mathrm{~nm}$ and showed a stable spherical shape with uniform surfaces and a unique internal morphology (Fig. 5E).

A closer observation into the inner structure by freezefracture SEM technique revealed many encapsulated siRNA-loaded nanoparticles embedded within the PLGA polymeric fibers forming a porous matrix surrounded by a dense polymeric wall (Fig. 8). The voids in the solid matrix served as a reservoirs for the siRNA-loaded nanoparticles. The structural integrity and the gene silencing activity of

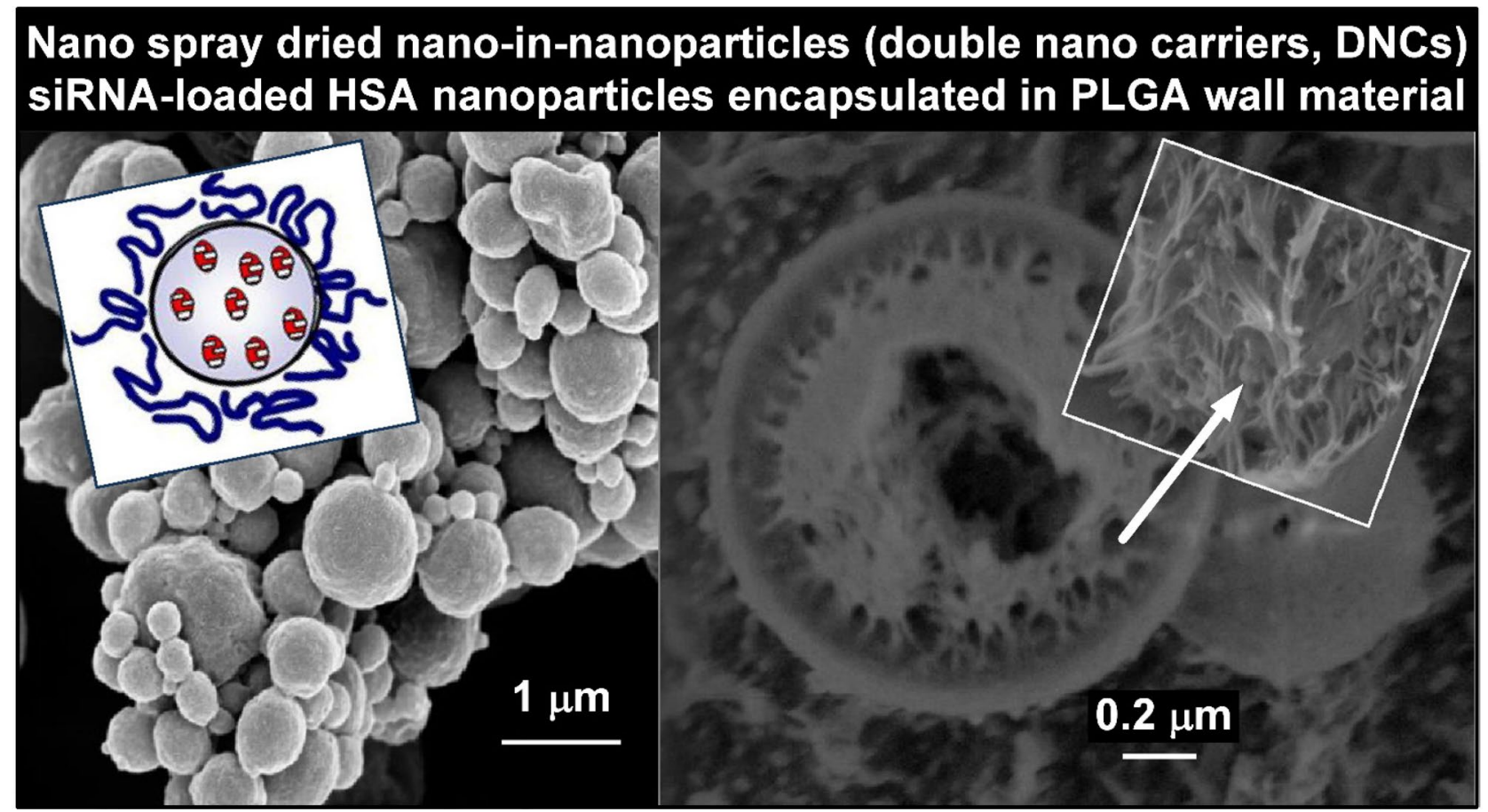

Fig. 8 Left: Nano spray dried nano-in-nanoparticles with about 580 to $770 \mathrm{~nm}$ mean size and schematic architecture of pegylated double nanocarriers (DNCs) loaded with siRNA. Right: Fractured DNC showing the inner structure composed of polymeric PLGA fibers with encapsulated human serum albumin primary nanoparticles (about $100 \mathrm{~nm}$ ) Adapted from Amsalem et al. (2017) 
the double encapsulated siRNA were fully preserved after encapsulation.

As expected, the release profile from the pegylated DNCs was more rapid (total siRNA release in $12 \mathrm{~h}$ ) than from the non-pegylated DNCs, releasing about $70 \%$ in the same time. Overall, these results demonstrated the potential use of DNCs as a novel platform for systemic delivery and controlled release of nucleic acids. This nano delivery invention, which uses this unique method of double nano-encapsulation to protect and control the release of active siRNA, was filed for patent by Benita et al. (2016). Therapeutics based on siRNA are considered promising for the treatment of a variety of genetic disorders and for the silencing transcription during gene expression.

The development of new cancer chemotherapeutics is a constant need. In this application area, Anzar et al. (2018) explored nano spray drying for the encapsulation of simvastatin in PLGA polymeric submicron particles. Simvastatin, which is typically used to lower cholesterol levels, has been investigated for the effective treatment of breast cancer. The process parameters were optimized to obtain dried spherical particles of $240 \mathrm{~nm}$ to $260 \mathrm{~nm}$ size utilizing a $7.0 \mu \mathrm{m}$ spray mesh (Fig. 5F). An encapsulation efficiency of $63 \%$ and a drug loading of $85 \mu \mathrm{g} / \mathrm{mg}$ were obtained. In vitro cytotoxicity studies revealed an enhanced anticancer activity with increasing drug concentration and exposure time. Overall, the nanoparticles were found to be appropriate for the treatment of solid tumor, e.g. breast cancer via intravenous administration.

Nanoparticle-loaded microparticles with a suitable aerodynamic diameter represent a promising approach for delivering nanoparticles into the lungs through dry powder inhalers. In this context, Torge et al. (2017) presented a drug delivery system of PLGA nanoparticles embedded in micron scaled mannitol particles. Mannitol is a sugar alcohol that is particularly advantageous as a matrix carrier for the treatment of bacterial infections in cystic fibrosis as an inhalable dry powder formulation. It is hygroscopic, increases mucus clearance, and improves the lung function. PLGA nanoparticles of about $170 \mathrm{~nm}$ in size were produced by emulsion-diffusion-evaporation technique $(\mathrm{O} / \mathrm{W}$ emulsion of $2 \%$ PLGA in ethyl acetate and $2.5 \%$ aqueous PVA solution).
PLGA nanoparticles and mannitol were then dried in various ratios using the nano spray drying process. The addition of PLGA nanoparticles to mannitol resulted in wrinkled, raisinshaped hollow particles with suitable aerodynamic properties (MMAD values between 3.6 and $5.4 \mu \mathrm{m}$ ). Most of the particles revealed a hollow morphology characterized by a distinct shell of mannitol and nanoparticles (Fig. 9).

The shell shape was explained by the higher Péclet number of nanoparticles compared to mannitol, which leads to faster drying at the droplet surface than diffusion of the substance within the droplet. The particles showed sufficient decomposition properties at high relative humidity, releasing morphologically unchanged PLGA nanoparticles. A maximum nanoparticle content of $20 \%$ was recommended to ensure a fast redispersion before particles are cleared.

By potentially encapsulating antibiotics in PLGA nanoparticles, this drug delivery system provides pulmonary treatment of Pseudomonas aeruginosa infections in cystic fibrosis patients. The microparticles enable the desired deposition in the lungs and the release of the nanoparticles, which can then penetrate the mucus barrier and release their agent in a controlled manner.

Dahili et al. $(2015,2017)$ crosslinked horseradish peroxidase (HRP) enzyme to nano spray dried PLGA (50:50, $8 \mathrm{kDa}$ ) carrier particles via amide bonds. Peroxidases play an important role in wastewater treatment due to their ability to oxidize and remove toxic phenol derivatives in the presence of hydrogen peroxide or alkyl hydroperoxide by forming insoluble polymers that can be precipitated from wastewater. Horseradish root is a commercial source of peroxidase. The majority of the nano spray dried PLGA carrier particles were between 1.2 and $5.4 \mu \mathrm{m}$ by using a $4 \mu \mathrm{m}$ spray mesh (Dahili et al. 2017) (Fig. 5J). The particles represented regular spherical shape with a smooth surface (Dahili and Feczkó 2015). The loading and activity of the immobilized HRP enzyme was enhanced by reducing the spray mesh size from 7.0 to $4.0 \mu \mathrm{m}$ as the surface-to-volume ratio of the PLGA particles increased. HRP crosslinked to the PLGA particles was reusable for up to four cycles with an efficiency of more than $30 \%$. The experiments showed that the fixed enzyme is a promising tool for the enzymatically removal of phenols from waste water.

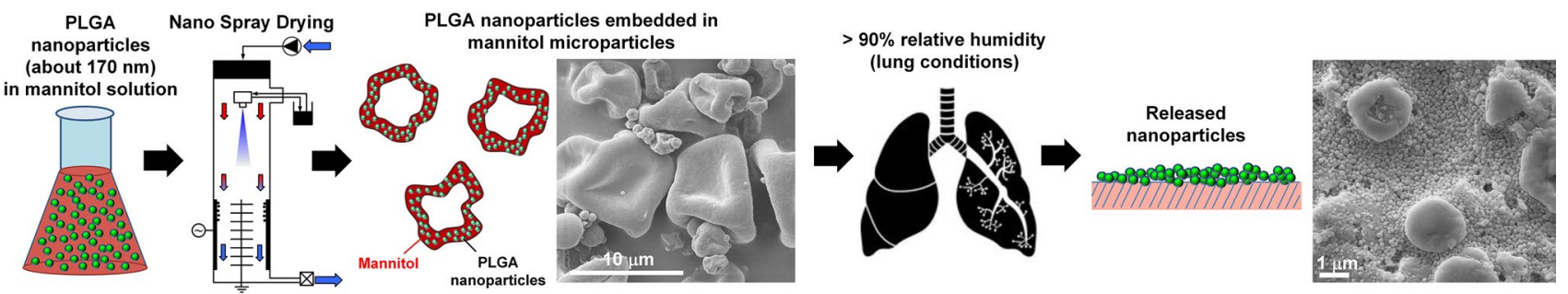

Fig. 9 PLGA nanoparticles embedded in mannitol microparticles for pulmonary drug delivery Adapted from Torge et al. (2017) 
Baghdan et al. (2018) presented a novel approach for coating small medical implants (e.g. dental implants) with nanoparticles of different biomaterials using nano spray drying. In this study, the electrostatic particle collector was utilized in a different approach (Fig. 10).

Dental implants were fixed on the electrostatic collector using conductive adhesive carbon tabs and PLGA particles were produced and deposited on the implants in a singlestep omitting the need of additional drying or washing steps. The implants were positioned $12 \mathrm{~cm}$ towards the bottom of the particle collector as this position was best suited to completely coat the implants with the smallest particles. The process parameters have been optimized to achieve small particle size, narrow size distribution and complete implants coverage. SEM showed spherical PLGA particles with a smooth surface in the range of $300 \mathrm{~nm}$ to $1.5 \mu \mathrm{m}$ with a peak size of about $615 \mathrm{~nm}$. The mean particle size on top of the collector tube was around $900 \mathrm{~nm}$, whereas the mean particle size decreased to around $300 \mathrm{~nm}$ on the bottom. These results were explained by the fact that larger particles have a higher surface charge and are therefore captured earlier by the electrostatic collector than smaller particles.

Further studies and applications notes were carried out to evaluate optimal drying conditions. Draheim et al. (2015) conducted a Design of Experiment (DoE) study on the nano spray drying of PLGA particles (50:50, 24 to $38 \mathrm{kDa}$, i.v. $0.41 \mathrm{dL} / \mathrm{g}$ ). The size of the particles was mostly influenced by the stabilizer, the organic solvent (e.g. acetone, DCM, ethyl acetate) and the polymer concentration (0.1 to 5\%). The addition of surfactant Span ${ }^{\circledR} 60$ optimized the performance of the vibrating mesh technology, while the organic solvent was the main factor influencing the yield. The highest yields of about $63 \%$ were achieved with acetone at $74{ }^{\circ} \mathrm{C}$ inlet drying temperature. The smallest PLGA particles measured by laser diffraction had an average size of about $2.4 \mu \mathrm{m}$ and were round and regularly shaped.

In an application note from Büchi Labortechnik AG (2011), PLA (Resomer ${ }^{\circledR}$ R202H) with a molecular weight of 10 to $18 \mathrm{kDa}$ (i.v. 0.16 to $0.24 \mathrm{dL} / \mathrm{g}$ ) was nano spray dried. A mixture of DCM and ethanol in a ratio of 70:30 (v/v) was found suitable for dissolving the PLA biopolymer. The outlet drying temperatures were kept well below the glass transition temperature of about 44 to $48{ }^{\circ} \mathrm{C}$. The PLA particles produced from $1 \%(\mathrm{w} / \mathrm{v})$ solid concentration were ranged from 0.4 to $4 \mu \mathrm{m}, 0.7$ to $7 \mu \mathrm{m}$, and 0.8 to $13 \mu \mathrm{m}$ depending on the spray mesh. The $7.0 \mu \mathrm{m}$ spray mesh resulted in larger particles and a wider size distribution. The yield was typically between 50 and $88 \%$ for 200 to $400 \mathrm{mg}$ sample amounts. Büchi Labortechnik AG (2009) also published the process parameters for producing spherical 0.5 to $5 \mu \mathrm{m}$ PLA (10 to $18 \mathrm{kDa})$ particles from a $2 \%(\mathrm{w} / \mathrm{v})$ solution in DCM with a $4.0 \mu \mathrm{m}$ spray mesh (Fig. 5I).

More recently, Büchi Labortechnik AG (2017) reported about nano spray drying of PLGA (50:50, 38 to $54 \mathrm{kDa}, \mathrm{T}_{\mathrm{g}}$ 46 to $50{ }^{\circ} \mathrm{C}$ ) solutions using the tall set-up of the Nano Spray Dryer B-90 HP in closed mode operation with the Inert Loop B-295 (Fig. 3). By nano spray drying 0.1\% (w/v) PLGA in a mixture of acetonitrile/water (95:5) and adding 0.005\% sodium acetate, spherical PLGA particles from $156 \mathrm{~nm}$ to $2 \mu \mathrm{m}$ were produced, the majority being below $1 \mu \mathrm{m}$ (Fig. 5L). The addition of the salt resulted in a conical spray with a throughput of about $106 \mathrm{~mL} / \mathrm{h}$ with the medium size

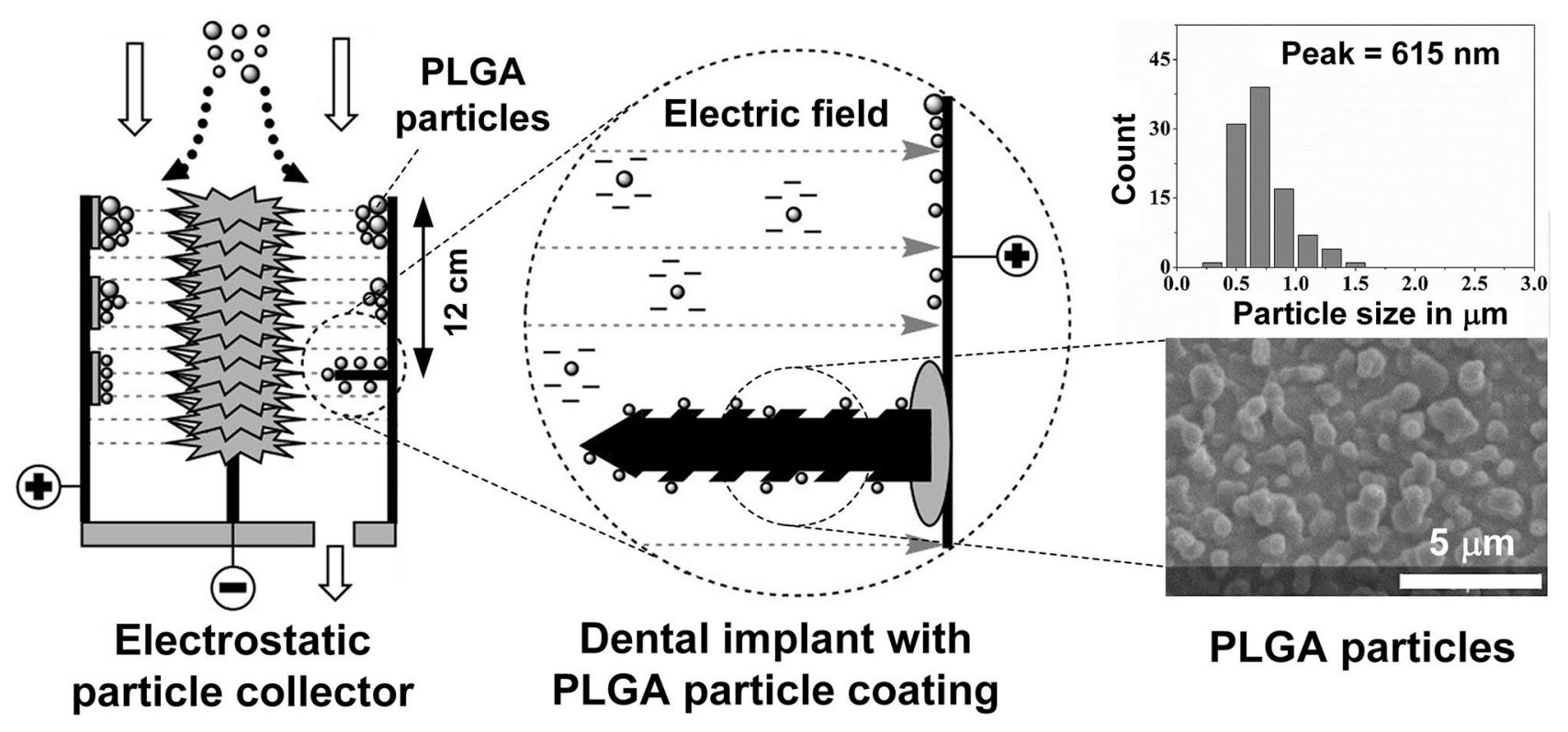

Fig. 10 Single-step PLGA particle coating for small dental implants produced by nano spray drying Adapted from Baghdan et al. (2018) 
spray mesh. The inlet temperature was set to $55^{\circ} \mathrm{C}$ resulting an outlet temperature of $36{ }^{\circ} \mathrm{C}$ (below $\mathrm{Tg}$ of 46 to $50{ }^{\circ} \mathrm{C}$ ). A 5-times higher throughput with similar particle size was observed in comparison to studies by Amsalem et al. (2017) with a $4 \mu \mathrm{m}$ spray cap of the 1 st generation of the Nano Spray Dryer B-90. This finding indicates that the medium size spray nebulizer of the Nano Spray Dryer B-90 HP corresponds approximately to the previous $4 \mu \mathrm{m}$ spray mesh.

\section{Conclusions and final remarks}

The research results reviewed in this study show the potential of nano spray drying as a relatively new approach and effective technology for encapsulating macromolecular therapeutics in biodegradable PLA/PLGA polymers and their derivatives. The data collected show the possibility of encapsulating different active ingredients in spherical particles and nano-in-nanoparticle composite structures for controlled drug delivery systems. Nano spray drying offers new possibilities for particle design and drug formulation, in the form of nano-micro composite particles from preformed nanoemulsions and nanosuspensions, hollow microparticles with nanoparticle-containing shells, or compact spheres from diluted solutions. The gentle drying conditions favour the production of typically spherical particles with a smooth or structured surface. The researched application fields are particularly the treatment of inhalation diseases (e.g. with sildenafil), inflammations (e.g. with dexamethasone), cancer (e.g. with simvastatin), immune diseases (e.g. with cyclosporine), genetic disorders (e.g. with siRNA-loaded nanoparticle therapeutics), the regulation of vasodilatation (e.g. nimodipine) or the surface coating of medical implants with biocompatible PLGA nanoparticles loaded with active substances. The Nano Spray Dryer B-90 from the Swiss company Büchi Labortechnik AG enables the production of smaller particles than in traditional spray dryers. The analyzed studies demonstrate the generation of PLGA particles from about $2 \mu \mathrm{m}$ to below $200 \mathrm{~nm}$. The nano- and submicron particles improve the bioavailability and release of bioactive components and drugs as a result of a higher surface volume, a higher penetration rate into the cells, higher stability, and the possibility of targeted release. The nano spray dryer offers the possibility to process small sample amounts of valuable drugs of a few $100 \mathrm{mg}$, such as siRNA-based therapeutics. The implemented core technologies are the vibration mesh technology for spray generation of droplets of a few micrometers, the electrostatic particle collector for the highly efficient detection of nanoscale particles, and the laminar drying gas flow for maintaining the stability and activity of heat-sensitive substances.

Depending on the application, optimized process parameters are found. The most important parameters are the inlet and outlet temperatures of the drying gas, the drying gas flow rate, the spray mesh size, the solids concentration, stabilizers and the organic solvent type. This gives engineers and scientists a whole range of formulation playgrounds. Dichloromethane, acetonitrile, or ethyl acetate were frequently used in the feasibility studies to dissolve the biopolymers. It is important that the outlet temperature does not exceed the glass transition temperature of the PLGA biopolymer to prevent softening and reducing the yield. Factors influencing the release of the active ingredient from PLGA particles are in particular the type of biopolymer, the ratio of lactide to glycolide, and the particle size. Smaller particles have a higher release rate than larger ones due to the difference in exposed surface area. In addition, the release kinetics in low molecular weight PLGA polymers is faster than in high molecular weight PLGA polymers due to higher hydrolysis and degradation rates.

It is foreseeable that the encapsulation of active pharmaceutical ingredients in PLA/PLGA biopolymers by nano spray drying will continue to increase as laboratory equipment becomes more widespread. In particular, nano spray drying technology is relatively easy to use, very versatile and allows parameter studies to be carried out on a laboratory scale.

In order to further explore the potential of nano spray drying, it is desirable to transfer this technology to industrial scale. There is an increasing need to scale-up this process to larger powder quantities, e.g. by multiplying the number of vibrating nebulisers. Further technological innovations in atomizer technology are expected to further reduce particle size.

\section{Compliance with ethical standards}

Conflict of the interest Cordin Arpagaus declares that he has no conflict of interest.

Statement of human and animal rights This article does not contain any studies with human or animal subjects performed by any of the authors.

Open Access This article is distributed under the terms of the Creative Commons Attribution 4.0 International License (http://creativecommons. org/licenses/by/4.0/), which permits use, duplication, adaptation, distribution and reproduction in any medium or format, as long as you give appropriate credit to the original author(s) and the source, provide a link to the Creative Commons license and indicate if changes were made.

\section{References}

Abdel-Mageed HM, Fouad SA, Teaima MH, Abdel-Aty AM, Fahmy AS, Shaker DS, Mohamed SA (2019) Optimization of nano spray drying parameters for production of $\alpha$-amylase nanopowder for 
biotheraputic applications using factorial design. Dry Technol. https://doi.org/10.1080/07373937.2019.1565576

Amsalem O, Nassar T, Benhamron S, Lazarovici P, Benita S, Yavin E (2017) Solid nano-in-nanoparticles for potential delivery of siRNA. J Control Release 257:144-155

Anzar N, Mirza MA, Anwer K, Khuroo T, Alshetaili AS, Alshahrani SM, Meena J, Hasan N, Talegaonkar S, Panda AK, Iqbal Z (2018) Preparation, evaluation and pharmacokinetic studies of spray dried PLGA polymeric submicron particles of simvastatin for the effective treatment of breast cancer. J Mol Liq 249:609-616

Arpagaus C (2009) Food technology at the nano scale: advances in spray drying. Food Eng. Ingredients 34:26-27

Arpagaus C (2011) Nano spray dryer B-90: literature review and applications, best@buchi Information Bulletin, Number 63/2011

Arpagaus C (2012) A novel laboratory-scale spray dryer to produce nanoparticles. Dry Technol 30:1113-1121

Arpagaus C (2018a) Pharmaceutical particle engineering via nano spray drying - process parameters and application examples on the laboratory-scale. Int J Med Nano Res. https://doi.org/10.23937 /2378-3664.1410026

Arpagaus C (2018b) Nano spray drying of pharmaceuticals. In: IDS 2018-21st international drying symposium, Valencia, Spain, 11-14 Sept 2018. pp 1-8

Arpagaus C (2018c) A short review on nano spray drying of pharmaceuticals. Nanomed Nanosci Res 546:1-5

Arpagaus C (2018d) Nano spray drying of pharmaceuticals. Am J Nanotechnol Nanomed 1:64-68

Arpagaus C Schafroth N (2007) Spray dried biodegradable polymers as target material for controlled drug delivery, best@buchi Information Bulletin, Number 46/2007

Arpagaus C, Meuri M (2010) Laboratory scale spray drying of inhalable particles: a review. Respir Drug Deliv 2:469-476

Arpagaus C, Schafroth N (2008) Spray drying of biodegradable polymers in laboratory scale. In: XVIth international conference on bioencapsulation, Dublin, Ireland, 4-6 Sept 2008. pp 1-4

Arpagaus C, Schafroth N (2011) Spray dried biodegradable polymers for controlled drug delivery systems. Eur Ind Pharm 11:10-13

Arpagaus C, Friess W, Schmid K (2009) Nano spray drying in laboratory scale. GIT Lab J 11-12:30-31

Arpagaus C, Schafroth N, Meuri M (2010a) Laboratory scale spray drying of inhalable drugs: a review, best@buchi Information Bulletin, Number 59/2010

Arpagaus C, Schafroth N, Meuri M (2010b) Laboratory scale spray drying of lactose: a review, best@ buchi Information Bulletin, Number 57/2010

Arpagaus C, Rütti D, Meuri M (2013) Chapter 18: enhanced solubility of poorly soluble drugs via spray drying. In: Douroumis D, Fahr A (eds) Drug delivery strategies for poorly water-soluble drugs. Wiley, New York, pp 551-585

Arpagaus C, John P, Collenberg A, Rütti D (2017) Chapter 10: Nanocapsules formation by nano spray drying. In: Jafari SM (ed) Nanoencapsulation technologies for the food and nutraceutical industries. Elsevier Inc., Amsterdam, pp 346-401

Arpagaus C, Collenberg A, Rütti D, Assadpour E, Jafari SM (2018) Nano spray drying for encapsulation of pharmaceuticals. Int $\mathrm{J}$ Pharm 546:194-214

Assadpour E, Jafari SM (2019) Advances in spray-drying encapsulation of food bioactive ingredients: from microcapsules to nanocapsules. Annu Rev Food Sci Technol 10:8-29

Baghdan E, Pinnapireddy SR, Vögeling H, Schäfer J, Eckert AW, Bakowsky U (2018) Nano spray drying: a novel technique to prepare well-defined surface coatings for medical implants. J Drug Deliv Sci Technol 48:145-151
Baras B, Benoit M-A, Gillard J (2000) Parameters influencing the antigen release from spray-dried poly(DL-lactide) microparticles. Int J Pharm 200:133-145

Beck-Broichsitter M, Schweiger C, Schmehl T, Gessler T, Seeger W, Kissel T (2012) Characterization of novel spray-dried polymeric particles for controlled pulmonary drug delivery. J Control Release 158:329-335

Beck-Broichsitter M, Paulus IE, Greiner A, Kissel T (2015a) Modified vibrating-mesh nozzles for advanced spray-drying applications. Eur J Pharm Biopharm 92:96-101

Beck-Broichsitter M, Strehlow B, Kissel T (2015b) Direct fractionation of spray-dried polymeric microparticles by inertial impaction. Powder Technol 286:311-317

Bege N, Renette T, Endres T, Beck-Broichsitter M, Hänggi D, Kissel T (2013) In situ forming nimodipine depot system based on microparticles for the treatment of posthemorrhagic cerebral vasospasm. Eur J Pharm Biopharm 84:99-105

Benita S, Amsalem O, Nassar T (2016) Nano delivery systems for SiRNA, US Patent 9421173 B2

Blanco MD, Sastre RL, Teijón C, Olmo R, Teijón JM (2005) 5-Fluorouracil-loaded microspheres prepared by spray-drying poly(D, L-lactide) and poly(lactide-co-glycolide) polymers: characterization and drug release. J Microencapsul 22:671-682

Bodmeier R, Chen H (1988) Preparation of biodegradable poly $( \pm)$ lactide microparticles using a spray-drying technique. J Pharm, Pharmacol, p 40

Büchi Labortechnik AG (2009) Nano spray dryer B-90 application note: PLA (Polylactic acid) R $202 \mathrm{H}$

Büchi Labortechnik AG (2010) Nano spray dryer B-90 Brochure, Flawil, Switzerland,. 11592236 en 1012. www.buchi.com

Büchi Labortechnik AG (2011) Application Note 002/2011 (Version A): Spray drying of polylactic acid (PLA) with the Nano Spray Dryer B-90

Büchi Labortechnik AG (2017) PLGA sub-micron particles by Nano Spray Drying, Application Note No.273/2017

Bürki K, Jeon I, Arpagaus C, Betz G (2011) New insights into respirable protein powder preparation using a nano spray dryer. Int $\mathrm{J}$ Pharm 408:248-256

Conte U, Conti B, Giunchedi P, Maggi L (1994) Spray dried polylactide microsphere preparation: influence of the technological parameters. Drug Dev Ind Pharm 20:235-258

Dahili LA, Feczkó T (2015) Cross-linking of horseradish peroxidase enzyme to fine particles generated by nano spray dryer B-90. Period. Polytech. Chem. Eng. 59:209-214

Dahili LA, Nagy E, Feczko T (2017) 2,4-Dichlorophenol enzymatic removal and its kinetic study using horseradish peroxidase crosslinked to nano spray-dried poly(lactic-co-glycolic acid) fine particles. J Microbiol Biotechnol 27:768-774

Danhier F, Ansorena E, Silva JM, Coco R, Le Breton A, Préat V (2012) PLGA-based nanoparticles: an overview of biomedical applications. J Control Release 161:505-522

Draheim C, de Crécy F, Hansen S, Collnot E-M, Lehr C-M (2015) a design of experiment study of nanoprecipitation and nano spray drying as processes to prepare PLGA nano- and microparticles with defined sizes and size distributions. Pharm Res 32:2609-2624

EVONIK (2011) RESOMER ${ }^{\circledR}$ Product range

Feng S-S, Mu L, Win K, Huang G (2004) Nanoparticles of biodegradable polymers for clinical administration of paclitaxel. Curr Med Chem 11:413-424

Feng AL, Boraey MA, Gwin MA, Finlay PR, Kuehl PJ, Vehring R (2011) Mechanistic models facilitate efficient development of leucine containing microparticles for pulmonary drug delivery. Int J Pharm 409:156-163 
Fu YJ, Mi FL, Wong TB, Shyu SS (2001) Characteristic and controlled release of anticancer drug loaded poly (D, L-lactide) microparticles prepared by spray drying technique. J Microencapsul 18:733-747

Garlotta D (2001) A literature review of poly(lactic acid). J Polym Environ 9:63-84

Heng D, Lee SH, Ng WK, Tan RBH (2011) The nano spray dryer B-90. Expert Opin Drug Deliv 8:965-972

Johansen P, Merkle HP, Gander B (2000) Technological considerations related to the up-scaling of protein microencapsulation by spray-drying. Eur J Pharm Biopharm 50:413-417

Kaialy W, Al Shafiee M (2016) Recent advances in the engineering of nanosized active pharmaceutical ingredients: promises and challenges. Adv Coll Interface Sci 228:71-91

Kulkarni RK, Pani KC, Neuman C, Leonard F (1966) Polylactic acid for surgical implants. JAMA Surg 93:839-843

Lee SH, Heng D, Ng WK, Chan H-K, Tan RBH (2011) Nano spray drying: a novel method for preparing protein nanoparticles for protein therapy. Int J Pharm 403:192-200

Li X, Anton N, Arpagaus C, Belleteix F, Vandamme TF (2010) Nanoparticles by spray drying using innovative new technology: the Büchi Nano Spray Dryer B-90. J Control Release 147:304-310

Masters K (1991) Spray drying handbook, 5th edn. Longman Scientific \& Technical, Harlow

O'Hara P, Hickey AJ (2000) Respirable PLGA microspheres containing rifampicin for the treatment of tuberculosis: manufacture and characterization. Pharm Res 17:955-961

Pamujula S, Graves RA, Freeman T, Srinivasan V, Bostanian LA, Kishore V, Mandal TK (2004) Oral delivery of spray dried PLGA/ amifostine nanoparticles. J Pharm Pharmacol 56:1119-1125

Panda A, Meena J, Katara R, Majumdar DK (2016) Formulation and characterization of clozapine and risperidone co-entrapped spraydried PLGA nanoparticles. Pharm Dev Technol 21:43-53

Pavanetto F, Genta I, Giunchedi P, Conti B (1993) Evaluation of spray drying as a method for polylactide and polylactide-co-glycolide microsphere preparation. J Microencapsul 10:487-497

Rivera PA, Martinez-Oharriz MC, Rubio M, Irache JM, Espuelas S (2004) Fluconazole encapsulation in PLGA microspheres by spray-drying. J Microencapsul 21:203-211

Schafroth N (2010) Nano-encapsulation of different actives in biodegradable polymers with Nano Spray Dryer B-90, Application Sheet No. 20100201, Büchi Labortechnik AG

Schafroth N, Arpagaus C, Jadhav UY, Makne S, Douroumis D (2012) Nano and microparticle engineering of water insoluble drugs using a novel spray-drying process. Coll Surf B Biointerfaces 90:8-15
Schmid K (2011) Spray drying of protein precipitates and Evaluation of the Nano Spray Dryer B-90. PhD Thesis, Ludwig-MaximiliansUniversity, Munich

Schmid K, Arpagaus C, Friess W (2009) Evaluation of a vibrating mesh spray dryer for preparation of submicron particles. Respir Drug Deliv 30:323-326

Schmid K, Arpagaus C, Friess W (2011) Evaluation of the nano spray dryer B-90 for pharmaceutical applications. Pharm Dev Technol 16:287-294

Schöttle IA (2006) Sprühgetrocknete Polylaktid, Poly(laktid-coglykolid) Mikropartikel zur Steuerung der Freisetzung aus pulmonalen Arzneiformen, Dissertation. Johannes Gutenberg-Universität Mainz

Schoubben A, Blasi P, Marenzoni ML, Barberini L, Giovagnoli S, Cirotto C, Ricci M (2013) Capreomycin supergenerics for pulmonary tuberculosis treatment: preparation, in vitro, and in vivo characterization. Eur J Pharm Biopharm 83:388-395

Sharma S, Parmar A, Kori S, Sandhir R (2016) PLGA-based nanoparticles: a new paradigm in biomedical applications. TrAC Trends Anal Chem 80:30-40

Torge A, Grützmacher P, Mücklich F, Schneider M (2017) The influence of mannitol on morphology and disintegration of spray-dried nano-embedded microparticles. Eur J Pharm Sci 104:171-179

Wagenaar BW, Müller BW (1994) Piroxicam release from spray-dried biodegradable microspheres. Biomaterials 15:49-54

Wan F, Yang M (2016) Design of PLGA-based depot delivery systems for biopharmaceuticals prepared by spray drying. Int J Pharm 498:82-95

Wang FJ, Wang CH (2002) Effects of fabrication conditions on the characteristics of etanidazole spray-dried microspheres. J Microencapsul 19:495-510

Wong TW (2015) Nanospray drying technology: existing limitations and future challenges. Recent Pat Drug Deliv Formul 9:185-186

Wong TW, John P (2015) Advances in spray drying technology for nanoparticle formation. In: Aliofkhazraei M (ed) Handbook of nanoparticles. Springer International Publishing, New York, pp $1-16$

Youan BBC (2004) Microencapsulation of superoxide dismutase into biodegradable microparticles by spray-drying. Drug Deliv J Deliv Target Ther Agents 11:209-214

Publisher's Note Springer Nature remains neutral with regard to jurisdictional claims in published maps and institutional affiliations. 